Máster Universitario en Enseñanza de Español/LE:

Lengua, Cultura y Metodología

Universidad de Granada

Curso 2012/14

\title{
Dificultades de aprendizaje en alumnos estonios. La enseñanza del género en el aula de ELE
}

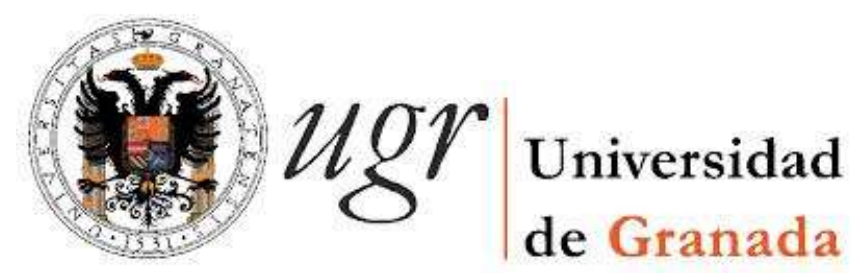

Trabajo realizado por: Nuria Alcaide García

Tutorizado por: Alejandro Castañeda Castro

Fecha de entrega: 10 de septiembre de 2014 


\section{ÍNDICE}

1. OBJETIVOS, JUSTIFICACIÓN Y ESTRUCTURA DEL TRABAJO ...6-7

2. ESTADO DE LA CUESTIÓN

2.1. El género gramatical en español

2.1.1. Definición de género gramatical.

2.1.2. Evolución del género del latín al español..................................8-10

2.1.3. Género no marcado y género marcado...................................10-11

2.1.4. Clases de género...................................................11-12

2.2. Adquisición del género en alumnos de español como segunda lengua....12-16

2.3. Presentación y tratamiento del género en el aula de español como lengua extranjera

2.3.1. El género en el Plan Curricular del Instituto Cervantes....

$16-18$

2.3.2. El género en los manuales y gramáticas de español como lengua extranjera.

3. PRINCIPALES CARACTERÍSTICAS DEL ESTONIO ...............23-26

4. ANÁLISIS DE ERRORES EN EL GÉNERO GRAMATICAL PRODUCIDOS POR ALUMNOS ESTONIOS ................................

4.1. Análisis y clasificación de errores según criterios morfológicos

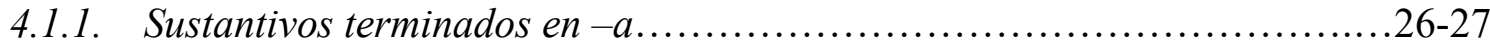

4.1.2. Sustantivos terminados en - e........................................27-28

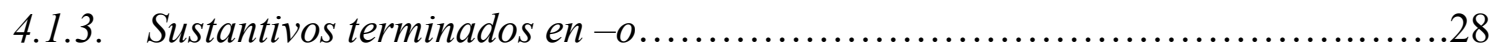

4.1.4. Sustantivos terminados en consonante....................................28-29

4.1.5. Concordancia con términos cercanos......................................29

4.1.6. Alteraciones en la morfología de las palabras para mantener la concordancia.

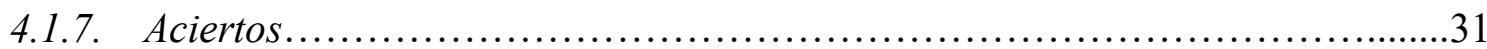

4.2. Análisis y clasificación de errores según criterios léxicos....................31

4.3. Análisis y clasificación de errores según criterios semánticos

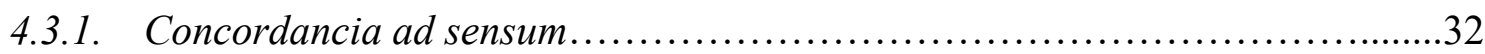

4.3.2. Concordancia con el hiperónimo de la clase léxica .........................32-33

4.3.3. Concordancia con el referente cultural..................................33

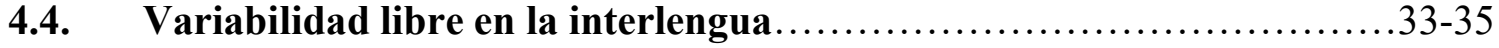


5. PROPUESTA DE ACTIVIDADES DIDÁCTICAS ...................35-38

6. CONCLUSIONES ................................................. $38-40$

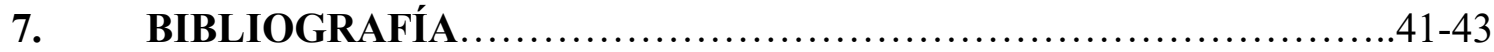

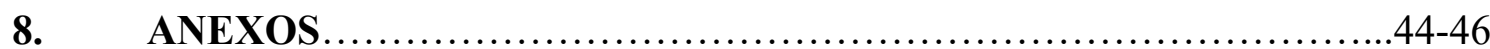


Resumen: Este trabajo consiste en un análisis de las dificultades que presentan los alumnos de español como lengua extranjera, especialmente los estonios, a la hora de aprender y adquirir el género gramatical. Este trabajo aborda esta cuestión del género gramatical desde un punto de vista teórico, descriptivo y didáctico. Se resumen las principales nociones del género gramatical en español y se presentan algunos cambios producidos en la evolución del latín al español. Este trabajo intenta clasificar y explicar el origen de los errores de género producidos por los alumnos. No solo se plantea una clasificación de errores sino que también se pretende describir el tratamiento y la importancia de la enseñanza del género en el aula de ELE a través del análisis de manuales didácticos.

Palabras clave: análisis de errores, género gramatical, enseñanza del español como lengua extranjera, adquisición, alumnos estonios.

\begin{abstract}
This work is an analysis of the difficulties presented by the students of Spanish as a foreign language, especially Estonians, when they learn and acquire grammatical gender. This paper addresses the issue of grammatical gender from a theoretical, descriptive and didactic perspective. The main notions of grammatical gender in Spanish are summarized and some changes in the evolution from Latin to Spanish are commented. This paper attempts to classify and explain the origin of gender errors produced by these students. It is not only a classification of errors but also it describes the treatment and the importance of gender in teaching language classroom through the analysis of training manuals.
\end{abstract}

Keywords: error analysis, grammatical gender, Spanish as a foreign language, acquisition, Estonian students. 


\section{OBJETIVOS, JUSTIFICACIÓN Y ESTRUCTURA}

Nuestro trabajo de fin de máster consiste en un análisis de errores en relación con el género gramatical producidos por alumnos estonios en el aprendizaje del español como lengua extranjera. Lo específico de nuestro tema y la acotación concreta a estudiantes estonios ha venido motivada por nuestra labor docente desarrollada en Estonia con diferentes grupos y niveles, donde hemos podido observar que el aprendizaje del género supone un gran reto para ellos, pues en su lengua materna no existe esta clasificación de sustantivos en femenino o masculino. Desde el punto de vista de la adquisición de la lengua para un no nativo, el uso asimilado del género supone un reto realmente complejo para nuestros alumnos. A priori, no tendría por qué entrañar mayor dificultad la elección del género para un sustantivo que tenga una relación directa con el sexo del ser que designa -independientemente de que nuestros alumnos tengan marca de género o no en su lengua materna-. Sin embargo, en un segundo momento, la elección del género puede llegar a complicarse al unirla al fenómeno de la concordancia del sustantivo con otros elementos del sintagma nominal como adjetivos y artículos. No obstante y sin duda alguna, nuestros alumnos experimentan una especial contrariedad a la hora de asignarle un género determinado a un sustantivo inanimado, ya que esta asignación acaba siendo en gran parte arbitraria. Es decir, el género plantea un problema de conceptualización (arbitrariedad de la asignación en nombres inanimados) y también un problema de automatización (control y fluidez en las operaciones relacionadas con la concordancia).

Por otro lado, después de haber analizado ampliamente los métodos de enseñanza, manuales y gramáticas de ELE, hemos podido constatar que la mayoría de estos materiales se enfocan desde un punto de vista muy generalista y con explicaciones muy limitadas en lo relativo al género. Es cierto que hay otros temas gramaticales que hasta ahora han venido a ocupar la primera línea teórica y académica en la enseñanza de ELE, sin embargo, creemos firmemente que la enseñanza del género debe ocupar una parte importante en la clase de ELE, ya que con una correcta asimilación y un buen aprendizaje por parte del alumno en los niveles iniciales se evitarán problemas futuros en niveles superiores. No tratar a tiempo y de una manera apropiada estos errores de nuestros alumnos en sus primeros años de aprendizaje, puede dar lugar a que se fosilicen y repercutir en su autoestima y motivación.

Por todos estos motivos, hemos creído conveniente hacer un análisis que nos ayude a sistematizar cuáles son los errores más recurrentes en relación al género en este 
tipo de alumnos, poder diagnosticar por qué los cometen, y extraer, finalmente, un patrón que nos ayude a proponer soluciones didácticas para mejorar la adquisición y asimilación del género desde los niveles iniciales.

Nuestro trabajo constará de cuatro amplias partes a través de las cuales desarrollaremos diferentes aspectos relativos al género, desde la teoría lingüística hasta las propuestas didácticas. La primera parte consistirá en un análisis del estado de la cuestión, que a su vez se relaciona con tres ámbitos: (1) la descripción gramatical de esta categoría, (2) los estudios que han abordado los procesos de adquisición de la misma por parte de estudiantes o aprendices extranjeros y (3) las reflexiones y propuestas disponibles sobre la didáctica del género. La segunda parte tratará de una presentación de las principales características del estonio, perteneciente a la familia lingüística ugrofinesa, haciendo especial hincapié en la ausencia de marca de género. La tercera parte consistirá en el análisis, clasificación e interpretación de los errores de alumnos estonios de niveles A1, A2 y B1 a lo largo de su aprendizaje del español como lengua extranjera. Estos datos han sido recogidos a través de diversas actividades donde las destrezas desarrolladas han sido la producción escrita, la expresión escrita y la interacción escrita. En la cuarta parte presentaremos una batería de actividades didácticas sobre el género para reforzar y afianzar su aprendizaje especialmente en los niveles iniciales. Por último, plantearemos unas conclusiones donde resumiremos las ideas principales de este trabajo, comentaremos nuestras limitaciones a la hora de presentar este trabajo de fin de máster y pergeñaremos futuras líneas de investigación que se puedan llevar a cabo utilizando nuestra propuesta didáctica como base de tal estudio.

\section{ESTADO DE LA CUESTIÓN}

\subsection{El género gramatical en español}

\subsubsection{Definición de género gramatical}

La Real Academia Española en la Nueva Gramática de la Lengua Española define el género como "la propiedad de los nombres y pronombres que tiene carácter inherente y produce efectos en la concordancia con los determinantes, los cuantificadores, los adjetivos y, a veces, con otras clases de palabras" (2009: 81). Debido a que el sustantivo ocupa una función nuclear dentro del sintagma nominal, impone su género a todos los demás componentes cumpliendo así una característica obligatoria del español como es la concordancia. 
Cuando se trata de sustantivos animados, el género sirve para diferenciar el sexo del referente, por ejemplo, La niña estaba contenta y el niño estaba muy enfadado. Sin embargo, cuando se trata de sustantivos inanimados, el género establece diferencias de otro tipo cuando es posible la alternancia $-o /-a$, por ejemplo: árbol-fruto: cerezocereza; diferencias de tamaño: barco-barca; o diferencia de forma: bolso-bolsa.

Como hemos mencionado anteriormente, la asignación del género de los sustantivos animados está relacionada directamente con el sexo biológico de su referente, mientras que la asignación del género de los sustantivos inanimados es totalmente arbitraria, y su uso consensuado ha experimentado un proceso largo y complejo en el que los hablantes decidieron inclinarse por una opción determinada. De hecho, dependiendo de la variedad diatópica que manejemos podemos notar algunas diferencias en la elección del género en sustantivos inanimados que viene a demostrar la arbitrariedad de la asignación del género. Para poder regular esta arbitrariedad Lozano Zahonero en la Gramática de Referencia de la Lengua Española apunta que

se pueden establecer ciertas tendencias que ponen en relación el género de los sustantivos inanimados con la clase léxica a la que pertenecen. El género de un sustantivo suele coincidir con el género del sustantivo que da nombre a la clase (hiperónimo), independientemente de su terminación. Así, por ejemplo, aunque el nombre de color acabe en -a, los nombres de colores son masculinos porque el hiperónimo color es masculino (el rosa, el naranja, el lila). Hay, sin embargo, otros casos en los que el hiperónimo resulta insuficiente para explicar el género (...) como en las notas musicales que a diferencia de la nota son siempre masculinas: el do, el re, el mi... (2010: 30)

\subsubsection{Evolución del género del latín al español}

Los sustantivos en latín podían ser masculinos (dominus-i), femeninos (rosa-ae), o neutros (templum-i). Como consecuencia, los adjetivos también presentaban tres formas distintas para concordar con el sustantivo: bonus (masculino), bona (femenino), bonum (neutro); miser (masculino), misera (femenino), miserum (neutro).

En el proceso de transformación del latín al español, el género neutro desapareció, ya que los sustantivos neutros latinos se distribuyeron entre los otros dos géneros: templum (neutro singular) > templo (masculino singular), capita (neutro plural) > cabeza (femenino singular). Los sustantivos neutros se encontraban en la $2^{\mathrm{a}}$, en la $3^{\mathrm{a}}$ y en la $4^{\mathrm{a}}$ declinación. Los sustantivos neutros de la $2^{\mathrm{a}}$ y $4^{\mathrm{a}}$ declinación, de tema en $-u-$, al perder la consonante final del nominativo singular y al abrirse la $-u$ en $-o$ se 
asimilaron a los sustantivos masculinos, que generalmente terminan en $-o$; por ejemplo, maleficium-ii (neutro) > maleficio (masculino). Por otro lado, los sustantivos neutros latinos que pasaron a femenino en español fueron tomados del nominativo y acusativo plural de la $2^{\mathrm{a}}$ y $4^{\mathrm{a}}$ declinación terminados en $-a$; por ejemplo arma (nominativo y acusativo neutro plural) > arma (femenino singular), folia (nominativo y acusativo neutro plural) > hoja (femenino singular). En cuanto a los sustantivos neutros de la $3^{\mathrm{a}}$, que por regla general terminaban en -us-oris, -en-inis, -ma-atis, -er-eris, -e -is, -al -alis, -ar -aris, la distribución no fue clara y se produjeron vacilaciones entre femenino y masculino: corpus-oris $>$ cuerpo (masculino) y mare-is $>$ mar (sustantivo ambiguo).

M. ${ }^{a}$ Jesús Torrens Álvarez en Evolución e historia de la lengua española (2007: 84) explica que aunque no existían desinencias específicas para cada uno de los géneros, sí que había un género que predominaba en cada una de las declinaciones: en la $1^{\text {a }}$ declinación rosa-ae de tema en $-a$, la inmensa mayoría de los sustantivos eran femeninos y solo unos pocos eran masculinos poeta-ae; de la misma manera que en la $2^{\mathrm{a}}$ declinación dominus- $i$ de tema en $-o$ y en la $4^{\mathrm{a}}$ declinación senatus- $u s$ de tema en $-u$, los sustantivos eran mayoritariamente masculinos, aunque también había sustantivos femeninos como manus-us. Por esta razón, como explica Lozano Zahonero, la regla general del género en español es la siguiente: "Son masculinos los sustantivos acabados en $-o$ y femeninos los sustantivos acabados en -a: el libro, la mesa, el niño/la niña" (2010: 25).

Las excepciones que presenta el español en cuanto al género ya eran casos excepcionales en el latín; por ejemplo, el femenino mano que proviene del sustantivo femenino latino manus-i de la $2^{\text {a }}$ declinación era uno de los pocos sustantivos femeninos en esta declinación predominantemente masculina. Torrens Álvarez comenta las vacilaciones y cambios que sufrieron los sustantivos femeninos en -us y los sustantivos masculinos en $-a$ :

Los pocos femeninos en -us se interpretaron como masculinos, como es el caso de varios nombres de árboles (ULMUS > olmo) o cambiaron su terminación, como los sustantivos de parentesco SOCRUS > latín vulgar SOCRA > suegra. Por su parte, los masculinos latinos en $-a$ vacilaron durante toda la Edad Media entre el masculino y el femenino, aunque con preferencia clara por el femenino. No obstante, finalmente se impuso el género etimológico, como se aprecia, por ejemplo, en los actuales masculinos en -a procedentes de los neutros griegos (clima, planeta, tema, profeta). Es excepción DIES > latín vulgar *DIA > día, considerado siempre masculino (2007: 84-85). 
Algunos de los sustantivos femeninos latinos que pertenecían a la $3^{\text {a }}$ declinación,

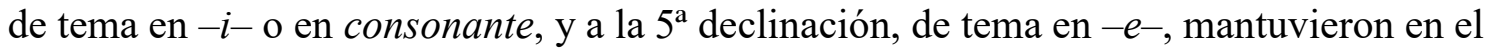
español medieval su género, pero, en algún punto de la evolución al español actual, sufrieron un cambio de género y hoy día son considerados masculinos; por ejemplo: amor, árbol, honor, origen, valle.

La distribución de los sustantivos neutros pertenecientes a estas declinaciones, no fue tan clara y organizada como los neutros de la $2^{\mathrm{a}}$ y la $4^{\mathrm{a}}$ declinación. En este caso, las vacilaciones entre masculino $\mathrm{y}$ femenino fueron numerosas $\mathrm{y}$ han tenido como resultado la existencia en el español actual de sustantivos ambiguos en cuanto al género. Lozano Zahonero define estos sustantivos como "sustantivos que designan en general seres inanimados y pueden usarse tanto en masculino como en femenino sin que ello conlleve un cambio de significado: el/la azúcar, el/la calor, el/la mar” (2010: 29).

Al consultar lo que la Nueva Gramática de la Lengua Española dice sobre el neutro, encontramos que el neutro no es considerado un tercer género aunque los demostrativos, los cuantificadores, los artículos y los pronombres personales sí puedan presentar una forma neutra:

El que los sustantivos no tengan género neutro y el que ningún adjetivo posea forma particular para concordar de esta manera con los pronombres son factores que llevan a pensar que el neutro no es propiamente un tercer género del español, equiparable a los otros dos, sino más bien el exponente de una clase gramatical de palabras que designan ciertas nociones abstractas (2009: $81)$.

\subsubsection{Género no marcado y género marcado}

Como bien explica Lozano Zahonero "el español es una lengua flexiva. Esto significa que hay palabras que tienen terminaciones diferentes según el género y el número, es decir, según sean masculinas o femeninas, singulares o plurales" (2010: 25). El sustantivo en español se compone de un lexema o raíz al que se le puede añadir una serie de morfemas gramaticales que van a marcar las categorías de género y número, componiendo así su paradigma flexivo: bajo, baja, bajos, bajas. En este paradigma se pueden observar la oposición masculino/femenino y la oposición singular/plural. Dentro de la oposición de género, el término no marcado es el masculino y el término marcado es el femenino. Ser el término no marcado de una oposición tiene una doble significación; por un lado, quiere decir que el masculino "se emplea en los contextos genéricos e incluye en su significado la designación de seres de ambos sexos, como en 
El oso polar es blanco" (Real Academia Española, 2009: 24); y por otro lado, significa que, en algunas ocasiones, el masculino es la forma por defecto, la que no muestra ciertos morfos específicos añadidos a la raíz y vinculados a la categoría en cuestión. Por ejemplo, en inglés - inglesa, sacerdote - sacerdotisa, la forma femenina es término marcado al incorporar material morfológico añadido asociado a la categoría de género en su variante femenina.

Como consecuencia de este carácter no marcado del masculino, la forma de masculino plural de los sustantivos que designan seres animados, en especial los que designan a personas, tiene un uso genérico; es decir, se usa el masculino plural para designar a todos los individuos de la clase o el grupo mencionado sin distinción de sexos: Los alumnos se manifestaron la semana pasada.

Lozano Zahonero aclara que "últimamente, sin embargo, es cada vez más frecuente hacer explícita la alusión a ambos sexos, sobre todo en el lenguaje político: compañeras y compañeros" (2010: 33), para evitar así provocar una posible discriminación sexista del lenguaje.

\subsubsection{Clases de género}

A la hora de clasificar los sustantivos, lo más común es dividirlos en sustantivos femeninos o masculinos, pero también existen sustantivos que pertenecen a categorías clasificables con otros términos más específicos. Estos son los sustantivos comunes, epicenos y ambiguos.

Según la RAE, los sustantivos comunes en cuanto al género "no experimentan cambios en su forma y hacen explícito su género indirectamente, es decir, mediante los determinantes o los adjetivos que los acompañan: el artista/la artista, este testigo/esta testigo" (2009: 83). Por tanto, los sustantivos comunes solo presentan una forma léxica (atleta) sin ninguna variación morfológica en la terminación.

La Academia nos sigue diciendo que los sustantivos epicenos son aquellos que se refieren a personas, animales o plantas mediante un único género gramatical, sea este masculino (el personaje, el rinoceronte) o femenino (la lechuza, la persona) (2009: 83). En el caso de los sustantivos epicenos que designan animales y plantas, los sustantivos hembra y macho sirven para deshacer la ambigüedad: el hipopótamo hembra, el hipopótamo macho; el espárrago hembra, el espárrago macho. Lozano Zahonero explica que en el caso de "los epicenos de persona, sin embargo, no es posible especificar el sexo: *la criatura varón, *el bebé hembra, *la víctima hombre, *el 
personaje mujer" (2010: 28); mientras que la RAE (2009: 84) especifica que si es necesario distinguir el sexo del referente, se prefiere emplear los términos masculino y femenino: el personaje femenino, la víctima masculina; o en algunos contextos, varón y mujer: el personaje varón.

La RAE define los sustantivos ambiguos como los que "poseen los dos géneros, pero no designan, por lo general, seres sexuados agravante, interrogante, maratón, pringue” (2009: 113). Lozano Zahonero (2010: 29) aclara que es frecuente que algunos de estos sustantivos sean ambiguos solo en singular y admitan, en cambio, un solo género en plural los azúcares, los mares, las artes. Como dice la RAE, "se dan a menudo ciertas diferencias geográficas, de registro, de frecuencia o simplemente de uso entre las dos variantes de los sustantivos ambiguos" (2009: 97). Por eso, en el caso del sustantivo el calor/la calor, la variante femenina no se emplea en el español estándar pero sí la usan los hablantes de español europeo meridional, del Río de la Plata y de ciertas zonas del área andina.

\subsection{Adquisición del género gramatical en alumnos de español como segunda lengua}

Para la elaboración de este apartado del trabajo vamos a comentar y resumir las principales conclusiones recogidas por Irma Alarcón en su artículo Grammatical Gender in Second Language Spanish (2014) sobre la adquisición del género gramatical y los distintos métodos y técnicas que se han utilizado para la investigación de esta cuestión gramatical del español.

Los aprendientes de español deben adquirir el género en sus sistemas de desarrollo. El género gramatical es considerado por Irma Alarcón una característica inherente e invariable que se almacena como parte de la información gramatical del sustantivo en el lexicón mental. Es decir, el género forma parte del conocimiento interiorizado de una lengua de un hablante, parte de la competencia lingüística del hablante; por eso, los errores de género y concordancia son muy poco frecuentes entre los nativos de español puesto que tienen el género interiorizado como parte de su competencia lingüística.

Existen, principalmente, dos tipos de estudios para llevar a cabo investigaciones acerca de la adquisición de lenguas: los estudios offline y los estudios online. Los estudios online se han empezado a usar en la última década para complementar a los estudios offline. Los estudios online estudian la adquisición de segundas lenguas (L2) en 
tiempo real, midiendo los procesos físicos de los alumnos durante la realización de las tareas para conseguir un mejor entendimiento del procesamiento de la información durante la comprensión y producción en curso. Los estudios offline miden el conocimiento gramatical del género a través de técnicas como la descripción de imágenes y tareas de juicio de gramaticalidad. Estos últimos han proporcionado útiles percepciones que ayudan a entender la adquisición del género pero han revelado muy poca información sobre este procesamiento de este aspecto del lenguaje en tiempo real; por eso, los estudios online rellenan este vacío de la investigación con más datos de la adquisición de una lengua extranjera en curso.

La investigación que aplica técnicas offline ha producido relevantes conclusiones en la adquisición del género gramatical en adultos de L2. Las conclusiones sacadas de estos estudios, sin embargo, pueden contradecirse: por ejemplo, un grupo de estudios offline, entre los que se encontraban la hipótesis de rasgos funcionales no incorporados (Failed Functional Features Hypothesis) (Hawkins y Chan, 1997), comprobaron que la adquisición del género está sujeta a un periodo crítico y solo puede ser adquirida por completo por un alumno adulto de español L2 si también está presente en la L1 del aprendiente; mientras que otros estudios que desarrollaban las hipótesis de transferencia completa y/o acceso completo (Full Transfer/Full Access Hypothesis) (Schwartz y Sprouse, 1996) e inflexión superficial ausente (Missing Surface Inflection Hypothesis) (Prévost y White, 2000), concluyeron que los estudiantes adultos de L2 son capaces de adquirir por completo las características gramaticales ausentes en su L1. En términos de representación mental, el género puede ser considerado adquirido a pesar de los errores ocasionales en la realización superficial. Los posibles errores que presenten son producidos por un problema en su actuación y no por una carencia en la competencia. Las pruebas mostraron que los aprendientes avanzados de español, con o sin género en la L1, se comportaban de manera similar a los nativos españoles (White et al, 2004).

Sin embargo, Franceschina (2005) demostró que las diferencias entre aprendientes con género en su L1 y nativos de español eran estadísticamente irrelevantes, mientras que la distancia entre aprendientes sin marca de género en su L1 y nativos de español sí era significativa. El proceso de adquisición del género en alumnos cuya lengua materna no posee esta marca gramatical es más difícil y tiene un mayor riesgo de error que el proceso de adquisición del género en alumnos con una L1 en la que sí existe tal propiedad gramatical. 
Otro grupo de estudios se centraron en el procesamiento de input, como, por ejemplo, el modelo de competición (Competition Model) (Bates y MacWhinney, 1987) que probó que cuando las pistas o señales lingüísticas de la L1 y de la L2 son similares, hay muy poca competición por la atención del aprendiente, y se produce una transferencia positiva. Pero cuando las pistas son desiguales se puede producir una transferencia negativa y complicar el aprendizaje de estas pistas de la L2. Estos estudios indican que los aprendientes de español son sensibles a las señales lingüísticas cuando procesan la concordancia de género, pero cuando animación y morfología aparecen juntas en el input, los alumnos prefieren la animación como una pista más fiable que la forma morfológica (Alarcón, 2010).

Algunas de las conclusiones sacadas de estudios offline coinciden con los resultados conseguidos en estudios de adquisición de la lengua por niños nativos de español. Los aprendientes de español como L2 al igual que los nativos de español son más precisos cuando los sustantivos designan a seres animados (Alarcón, 2010; PérezPereira, 1991) ya que tienen como referencia el sexo biológico del ser designado a la hora de elegir entre género masculino o femenino. En cambio, se producen más errores de concordancia cuando el sustantivo tiene un referente inanimado. En cuanto a la asignación del género, las pruebas presentan una mayor tendencia por el uso del masculino como género por defecto tanto por alumnos de L2 como por los niños hispanohablantes. Otra coincidencia en la adquisición por parte de aprendientes y de nativos tiene que ver con el efecto de la congruencia de género en la concordancia: los contextos congruentes de género facilitan el procesamiento, mientras que las situaciones incongruentes lo inhiben. Los niños y los aprendientes de L2 actúan mejor en contextos en los que hay una correlación directa con el género.

La investigación psicolingüística en la adquisición del género español por alumnos de L2 se sirvió de los estudios y técnicas online, que están diseñadas para evaluar la competencia subyacente durante el procesamiento en tiempo real. La adquisición completa del género implica una doble adquisición: (1) la adquisición del conocimiento gramatical implícito del género, es decir, su representación mental; (2) la adquisición de la computación rápida y eficiente, o sea, su procesamiento y producción automatizada. Dada esta doble adquisición, la investigación psicolingüística empleó las técnicas online o en curso para investigar el conocimiento y la computación a tiempo real. 
Algunas de las conclusiones que se han conseguido de estos estudios son las siguientes: Keating (2009) investigó los efectos de la distancia sintáctica en el procesamiento de la concordancia de género comparando la concordancia con adjetivos que eran adyacentes al sustantivo, o sea en posición atributiva, y adjetivos en otro sintagma sintáctico, en posición predicativa. Comprobando los movimientos de los ojos de los nativos y de los aprendientes de L2, Keating encontró que los aprendientes avanzados, actuaban como los hablantes nativos únicamente en el caso de los adjetivos atributivos. Esto quiere decir que los aprendientes son sensibles solo a los errores de género de los complementos cercanos al núcleo.

Otra conclusión interesante: Alarcón (2009) también comprobó que los aprendientes de L2 encuentran en la animacidad una importante pista lingüística para el establecimiento de la concordancia correcta de género, al igual que los hablantes nativos. Los participantes del estudio fueron considerablemente más rápidos con los núcleos nominales animados que con los inanimados. Por eso, teniendo en cuenta la animacidad, el procesamiento de género entre los aprendientes de L2 es similar al de los nativos.

Una última conclusión importante tiene que ver con los errores fosilizados: los resultados de estudios sobre la asignación del género y la concordancia en la producción oral espontánea muestran que los alumnos avanzados e incluso los casi nativos tienen dificultades persistentes. Estos errores de producción parecen ser sistemáticos ya que se observan patrones de errores en la producción y en la comprensión; por ejemplo, la mayoría de los errores se producen con sustantivos que no terminan ni en $-o$ ni en $-a$ y no concuerdan morfológicamente con el sexo biológico (Alarcón, 2011). El problema que encontramos en estos casos es la fosilización. Según White la fosilización "is attributable not to a breakdown in the grammar as such but, rather, to some kind of unreliability in the interface between the syntax and other areas of the grammar" (2003:201). Entonces, la fosilización no es un déficit de representación sino un problema que implica más bien la relación de los rasgos abstractos con su correspondiente morfología inflexional.

Para finalizar, podemos añadir que las conclusiones extraídas de estos estudios, a saber, que (1) los alumnos con marca de género en su L1 presentan menos problemas para el aprendizaje y la adquisición del género en la L2; que (2) los alumnos, al igual que los nativos, adquieren antes y mejor los sustantivos animados; que (3) el masculino es el género que usan por defecto; que (4) el distanciamiento sintáctico del referente y 
sus componentes influye en la producción de errores; que (5) existen problemas de fosilización de errores con sustantivos que acaban en otra vocal que no es ni $-o$ ni $-a$; todos estos hallazgos, decimos, nos ayudan a diagnosticar con precisión cuáles son los principales problemas y obstáculos a la hora de tratar el género en el aula de ELE y a justificar la pertinencia de nuestro presente trabajo.

\subsection{Presentación y tratamiento del género en el aula de español como lengua extranjera}

2.3.1. El género en el Plan Curricular del Instituto Cervantes

En el Plan Curricular del Instituto Cervantes (2007) la enseñanza del género gramatical aparece distribuida de la siguiente manera:

\begin{tabular}{|c|c|}
\hline \multicolumn{2}{|c|}{ 1.2. El género de los sustantivos } \\
\hline A1 & $A 2$ \\
\hline $\begin{array}{l}\text { - Masculino en -o y femenino en -a } \\
\text { amigo, vecino, libro } \\
\text { amiga, vecina, casa } \\
\text { - Masculino / femenino } \\
\text { - Vocales que no sean -o / -a } \\
\text { el peine, la muerte } \\
\text { - Consonante } \\
\text { el árbol, la catedral, la solución, el corazón } \\
\text { - Femenino en -o } \\
\text { - Procedente de una abreviación } \\
\text { la moto / motocicleta, la foto / fotografia, la radio / } \\
\text { radiodifusión } \\
\text { - Heteronimia } \\
\text { el padre / la madre, el hombre / la mujer }\end{array}$ & $\begin{array}{l}\text { - Masculino / femenino en -i / -ú (más frecuente en } \\
\text { masculino) } \\
\text { el jabalí } \\
\text { - Masculino en -a } \\
\text { - Nombres de colores } \\
\text { el naranja, el rosa } \\
\text { - Sustantivos terminados en -ma } \\
\text { el problema, el tema } \\
\text { - Otros casos aislados } \\
\quad \text { el dia } \\
\text { - Femenino en -o } \\
\text { - Casos aislados } \\
\quad \text { la mano } \\
\text { - Género diferente expresado con una terminación } \\
\text { diferente: fernenino en -esa, -triz, -ina, -isa } \\
\text { el príncipe / la princesa, el actor / la actriz, el rey / } \\
\text { la reina, el poeta / la poetisa } \\
\text { - Sustantivos terminados en -dor, -tor, -sor } \\
\text { el gobernador / la gobernadora, el director, el } \\
\text { secador, el profesor } \\
\text { - Sustantivos invariables: el género se sabe por el } \\
\text { articulo } \\
\text { - Nombres de persona terminados en -ista } \\
\text { el / la artista, el / la pianista }\end{array}$ \\
\hline
\end{tabular}

Fuente: Instituto Cervantes, Plan Curricular del Instituto Cervantes, Centro Virtual Cervantes. 


\begin{tabular}{|c|c|}
\hline B1 & B2 \\
\hline $\begin{array}{l}\text { - Términos con género distinto en las variedades del } \\
\text { español } \\
\text { la bombilla [España] / el bombillo [México, América } \\
\text { Central, Las Antillas, Colombia y Venezuela] } \\
\text { el bolso, la costumbre [España] / la bolsa, el } \\
\text { costumbre [parte de México, Costa Rica y Colombia] } \\
\text { el salón [España] / la sala [Hispanoamérica] } \\
\text { - Nombres epicenos } \\
\text { la persona, la víctima, el delfín macho / hembra } \\
\text { - Cambio de género expresa cambio de significado: } \\
\text { árbol / fruto } \\
\text { el manzano / la manzana, el naranjo / la naranja } \\
\text { - Sustantivos invariables: el género se sabe por el } \\
\text { artículo } \\
\text { - Casos aislados } \\
\text { el / la guía, el / la colega, el / la testigo }\end{array}$ & $\begin{array}{l}\text { - Sustantivos femeninos que empiezan con a- tónica } \\
\text { acentuada con artículo y cuantificador en masculino } \\
\text { singular } \\
\text { el aula / las aulas / esta aula / nuestra aula / la } \\
\text { amplia aula } \\
\text { el agua / las aguas / ciertas aguas / las frescas } \\
\text { aguas / toda el agua } \\
\text { - Femenino en -triz, -ez, -dad, -ción, -sión, -tud, } \\
\text {-umbre (de cosa) } \\
\text { la cicatriz, la vejez, la ciudad, la sensación, la } \\
\text { ocasión, la actitud, la costumbre }\end{array}$ \\
\hline
\end{tabular}

Fuente: Instituto Cervantes, Plan Curricular del Instituto Cervantes, Centro Virtual Cervantes.

\begin{tabular}{|c|c|}
\hline \multicolumn{2}{|c|}{ 1.2. El género de los sustantivos } \\
\hline C1 & $\mathrm{C2}$ \\
\hline $\begin{array}{l}\text { - Cambio de género expresa cambio de significado } \\
\text { - Individual / colectivo } \\
\text { el leño / la leña, el fruto / la fruta } \\
\text { - Grande / pequeño } \\
\text { el huerto / la huerta, el cuchillo / la cuchilla, el } \\
\text { jarro / la jarra } \\
\text { - Significado totalmente diferente } \\
\text { el frente / la frente, el orden / la orden, el coma / } \\
\text { la coma } \\
\text { - Sustantivos ambiguos: masculinos y femeninos } \\
\text { el mar / la mar, el color / la color, el azúcar / la } \\
\text { azúcar }\end{array}$ & $\begin{array}{l}\text { - [Hispanoamérica] Tendencia a distinguir el género de } \\
\text { ciertos sustantivos que no tienen marca de género en el } \\
\text { español estándar y a crear formas femeninas en -a o } \\
\text { masculinas en -o } \\
\text { estudianta, tigra, sapa } \\
\text { pianisto, maquinisto... }\end{array}$ \\
\hline
\end{tabular}

Fuente: Instituto Cervantes, Plan Curricular del Instituto Cervantes, Centro Virtual Cervantes.

Según el Plan Curricular del Instituto Cervantes, los alumnos de nivel A1 se tienen que familiarizar con la regla general de formación de palabras masculinas y femeninas, mientras que en A2 empiezan a ver las excepciones a esa regla general, aprenden nuevas terminaciones para cada género y se encuentran con algunos sustantivos comunes relativos a las profesiones. En B1, los alumnos se enfrentan a las variedades dialectales, a los sustantivos epicenos y a algunos sustantivos inanimados en los que el cambio de morfema $-o /-a$ implica un cambio de significado. Es curioso que sea en B2 cuando el Instituto Cervantes incorpore como contenido el hecho de que los sustantivos femeninos que comienzan por /a/ tónica vayan precedidos por un artículo masculino y no femenino para evitar el fenómeno de la cacofonía, mientras que en 
algunos manuales, como por ejemplo Aula Internacional I Nueva Edición (Difusión, año) aparece como un contenido del tema 2 "Quiero aprender español” para el nivel A1. Es importante comentar que en los niveles avanzados, $\mathrm{C} 1$ y $\mathrm{C} 2$, los contenidos relativos al género tienen que ver con aspectos más específicos, con casos particulares y con las variedades del español de Hispanoamérica.

\subsubsection{El género en los manuales y gramáticas de español como lengua extranjera}

La mayoría de manuales de español actualizados han adoptado como métodos desde el que orientar la enseñanza del español los conocidos como "enfoque comunicativo" y “enfoque por tareas". Como consecuencia de esta perspectiva didáctica, la enseñanza de cualquier elemento gramatical está subordinada al papel que la gramática juega en el desempeño de la tarea propuesta por las actividades del tema, sin profundizar demasiado en explicaciones teóricas sobre algunos aspectos concretos del contenido gramatical que se está usando, y tratándose a veces de manera muy superficial y sucinta. Son numerosos los estudios que respaldan los beneficios del enfoque comunicativo y no es nuestro objetivo cuestionarlo aquí, pero sí creemos que sería aconsejable que los profesores tuvieran en cuenta las posibles carencias que pueda tener y suplirlas así con su buen hacer y sus explicaciones gramaticales pertinentes, para llegar así a un equilibrio óptimo entre los beneficios que pueda tener el enfoque formal y el comunicativo, ya que el conocimiento de la gramática es esencial para poder comunicarse de manera correcta y evitar errores en el acto comunicativo. Uno de los problemas del enfoque comunicativo y de su poca atención al contenido gramatical es el hecho de que los alumnos no desarrollan los saberes gramaticales y esto causa la fosilización de muchos errores. Es cierto que la adquisición efectiva de un recurso gramatical se da en un entorno comunicativo, pero, para conseguirlo, primero el alumno tiene que procesar cierto contenido gramatical, después debe procesar los aspectos lingüísticos asociados a la expresión de ese contenido, y, por último, establecer correspondencia "forma-contenido". Si a estas pequeñas deficiencias en el enfoque comunicativo que adoptan los principales manuales de enseñanza de ELE, les sumamos que el género gramatical es uno de los contenidos menos tratados en el aula por culpa de la escasa atención en los manuales, pueden llevar a los alumnos al aprendizaje memorístico sin sentido práctico alguno y a la ya citada fosilización de errores.

Hemos analizado el tratamiento del género en los manuales Nuevo Prisma A1: Curso de Español para Extranjeros (2012), de la editorial Edinumen; Aula 
Internacional 1. Nueva edición (2013) para nivel A1 y Aula Internacional 2 (2005) para nivel A2, los dos de la editorial Difusión; Meta Final ELE. Curso de español rápido (2012) para los niveles A1, A2 y B1.1., de la editorial Edelsa. De estos manuales vamos a comentar algunos aspectos positivos sobre el tratamiento del género gramatical y también a criticar algunos puntos mejorables en la explotación didáctica.

En los manuales citados de nivel A1 encontramos el género como contenido de los temas iniciales, es decir, se considera un contenido gramatical básico del español desde el mismo principio. Sin embargo, aunque se presenta como contenido gramatical, su aprendizaje y comprensión plena no aparece como un objetivo, el único objetivo es la utilización funcional relacionada con el acto comunicativo sin más. El primer contacto del alumno con el género se da en el apartado de las nacionalidades, cuando los alumnos aprenden a presentarse y decir de dónde son y en qué trabajan o a qué se dedican. Por ejemplo, en Prisma y en Meta ELE, el ejercicio relacionado con las nacionalidades presenta el mismo estilo: se trata de un ejercicio reflexivo donde el alumno tiene que pensar en las formas dadas para poder completar una tabla con las nacionalidades en sus distintas formas: masculino singular, femenino singular, masculino plural y femenino plural. Tras el ejercicio, el alumno se encuentra con un cuadro donde se presenta la regla general del género gramatical de manera muy escueta. Sin duda, es algo muy positivo que el alumno establezca las relaciones entre los distintos procedimientos para la formación del femenino y del masculino basándose en ejemplos. No obstante, es bastante probable que los alumnos se encuentren un poco perdidos durante la realización de un ejercicio en el que se mezclan formas de variación $-o /-a$ con formas invariables, como estadounidense o belga sin que se dé ningún tipo de información o aclaración previa. En Aula Internacional I, el primer contacto con el género se da en un ejercicio de presentación donde los alumnos deben rellenar las fichas con los datos personales (nombre, nacionalidad y profesión) de cinco personas cuyas fotos están presentes en el ejercicio para servir como apoyo visual en la realización del mismo. En comparación con los ejercicios anteriores, este ejercicio es más fácil, pues el alumno tiene debajo de cada foto la descripción que ha hecho cada persona sobre sí misma, ellos solo deben identificar las palabras que son nacionalidades o profesiones. El problema reside en el hecho de que los ejercicios posteriores ya no presentan el género de nuevo para proseguir con el acercamiento de los alumnos a esta propiedad gramatical, sino que están destinados a los verbos necesarios para presentarse, por ejemplo, llamarse y ser o a las fórmulas de saludo y despedida. 
En cuanto a ejercicios específicos de género, hay que destacar que son muy escasos en los manuales, ya que empiezan a ser relacionados con otros aspectos gramaticales también asociados al sustantivo como son los artículos o la propiedad del número. En Prisma hay una secuencia de ejercicios que consta de tres partes. La primera consiste en un ejercicio que pide a los alumnos usar el diccionario para buscar el género de una serie de palabras. Es un buen ejercicio de introducción al género pues el alumno va a conocer que no todas las palabras femeninas terminan en -a (ciudad, lección), que no todas las palabras masculinas terminan en -o (mapa, tema, día) y que hay palabras comunes en cuanto al género (estudiante). También es un ejercicio beneficioso, pues el alumno empieza a conocer el diccionario monolingüe y a entender las marcas de las entradas (com., $f$., m.). Después de este ejercicio, los alumnos tienen que completar un cuadro de explicación gramatical donde deben leer las reglas y completarlas usando como ejemplos los sustantivos que han buscado anteriormente. Este ejercicio les hace reflexionar e interpretar las reglas de manera que el alumno empieza a tomar conciencia del género y de muchas de sus variantes. Como última parte de la secuencia, los alumnos se encuentran con cuatro grupos de palabras donde tienen que identificar el sustantivo intruso; por ejemplo, del primer grupo de sustantivos, los alumnos deben identificar como intruso el sustantivo estudiante pues es común y no masculino como libro, bolígrafo y cuaderno. De esta manera los alumnos recapacitan de manera práctica sobre lo que han aprendido.

En Aula Internacional I son escasos los ejercicios específicos de género, el único que podemos encontrar es un ejercicio introductorio del tema de los artículos determinados. El alumno tiene que decidir si las palabras del ejercicio son masculinas y femeninas en la primera actividad. Después, tienen un pequeño ejercicio donde deben unir el inicio y el final de las reglas generales del género basándose en las terminaciones de los sustantivos anteriores. Como ejercicio final, el alumno debe leer dos diálogos donde los artículos determinados están en negrita, y completar un cuadro donde se acaben presentando las distintas formas del artículo determinado. En comparación con la secuencia de actividades de Prisma, Aula Internacional I pretende que el alumno entienda el género de los sustantivos para una correcta elección del artículo determinado, puesto que no presta más atención a las variedades que se presentan en el género y en los distintos procedimientos de formación de femenino. La carencia informativa que se da en esta secuencia, se intenta suplir con la parte gramatical de todos los temas de Aula Internacional I. En cada tema, el alumno cuenta con una página 
donde se recogen todos los aspectos gramaticales que contiene el tema y una pequeña explicación.

Meta ELE también carece de ejercicios específicos de género. Por tratarse de un curso rápido de español, en el primer ejercicio relacionado con el género, el alumno tiene que identificar no solo las formas de género, sino también de número y, además, en el mismo ejercicio aparecen los artículos determinados y los indeterminados. Creemos que es un ejercicio demasiado complejo para un alumno inicial, tiene demasiada información nueva que el alumno no puede procesar adecuadamente y no dispone de unos ejercicios posteriores que lo ayuden a comprender y asimilar las formas y a poner esos conocimientos en práctica. Como ejercicios específicos para el aprendizaje de género, Meta ELE presenta una serie de actividades de repaso del tema 1 donde solo tres están relacionados únicamente con el género y no con otras cuestiones gramaticales. En estos ejercicios, el alumno clasifica los sustantivos en masculinos o femeninos, relaciona algunas terminaciones con el género y escribe la forma femenina de cuatro sustantivos.

En cuanto a la enseñanza de la concordancia, el manual de Prisma presenta un desarrollo de actividades más apropiado que el resto de manuales analizados, ya que lleva al alumno de unos ejercicios específicos de género a una serie de actividades que van incrementando la dificultad. Después de la secuencia sobre el género, descrita anteriormente, los alumnos se encuentran con ejercicios sobre el número, después sobre el articulo determinado y por último, un ejercicio compuesto de tres apartados de los cuales el primero es un ejercicio de procesamiento de input donde el alumno lee unas frases asociadas a unas imágenes para al comparar con el resto, ver las diferencias que se producen en los artículos y en los colores: los arboles son verdes; el humo es gris; las nubes son blancas; la noche es negra; etc. El segundo apartado es otra tabla de información gramatical donde el alumno tiene que reflexionar sobre los ejemplos del ejercicio anterior y completar los huecos de las reglas gramaticales. Y el tercer y último apartado de este ejercicio es un ejercicio de producción escrita donde el alumno tiene que describir de qué color son los objetos presentados. En resumen, el alumno ha ido aprendiendo las cuestiones relacionadas con el género de manera progresiva. De este modo, se evita la confusión que pueden crear por ejemplo los ejercicios de Meta ELE, donde en un mismo ejercicio, el alumno tiene que procesar mucha información diferente sin llegar a afianzarla de una manera apropiada. 
Es importante comentar que esta escasez es mayor en manuales de niveles superiores. Por ejemplo, al analizar el manual de Aula Internacional 2 para nivel A2, no encontramos ejercicios sobre género en concreto y, como consecuencia, en las partes destinadas a explicación gramatical, no vemos ninguna explicación relativa al género ni a los aspectos de este que son adecuados para este nivel. También hemos analizado la parte de contenidos de B1.1 de Meta ELE, y hemos notado que el género ya no aparece y que los contenidos se centran más en el modo subjuntivo y en los distintos tiempos de pasado.

Por otro lado, las gramáticas pedagógicas como la Gramática Básica del Estudiante de Español (2005), de la editorial Difusión, y la Gramática de Uso del Español. Teoría y Práctica (2008), de la editorial SM, sí presentan más variedad de actividades y ejercicios que abordan sistemáticamente algunos de los aspectos comentados. Estas gramáticas de español son un apoyo tanto para el docente como para el aprendiente ya que complementan y refuerzan el trabajo en el aula. Con respecto al género, el tratamiento es similar en ambas gramáticas ya que aparece dividido en dos apartados: el género de los sustantivos inanimados y el de los sustantivos animados. En cuanto a la explicación del género, la diferencia más notable entre estas gramáticas reside en el hecho de que la Gramática Básica, desde el principio, presenta el fenómeno de la concordancia como una característica inherente al género de los sustantivos mientras que en la Gramática de Uso no hay ninguna referencia a esta propiedad en ninguno de los dos apartados. Los ejercicios presentados en las dos gramáticas son para alumnos de niveles iniciales (A1 y A2) aunque ambas sean gramáticas destinadas también a alumnos de niveles intermedios: B1 en el caso de la Gramática Básica y B2 en el caso de la Gramática de Uso. Esto quiere decir que no se encuentran ejercicios donde se traten los sustantivos epicenos ni los sustantivos ambiguos. A pesar de esta falta de actividades destinadas a alumnos de niveles intermedios, estas dos gramáticas de enseñanza del español son un instrumento útil para la profundización y automatización de este aspecto de la gramática en los alumnos de niveles iniciales.

En resumen, a causa de la mínima proporción de ejercicios sobre el género en los manuales, este no es tratado en profundidad en las aulas de ELE y los alumnos no llegan a tener un dominio adecuado sobre esta categoría gramatical que es una de las bases del español, asegurando un mayor riesgo de fosilización de errores. 


\section{PRINCIPALES CARACTERÍSTICAS DEL ESTONIO}

El estonio pertenece al grupo lingüístico balto-finés de la familia ugrofinesa junto con el carelio, el vepsio, el ingrio, el livonio y el votiaco. En la imagen siguiente podemos comprobar el resto de las lenguas pertenecientes a esta familia lingüística. Además del grupo balto-finés, las lenguas ugrofinesas se dividen en: el lapón o sami; el grupo volgafinés, formado por el mordavo y el mari; el grupo pérmico, compuesto por el komi y el udmurto; y las lenguas ugrias donde se encuentra el húngaro, el vogul y el ostiaco.

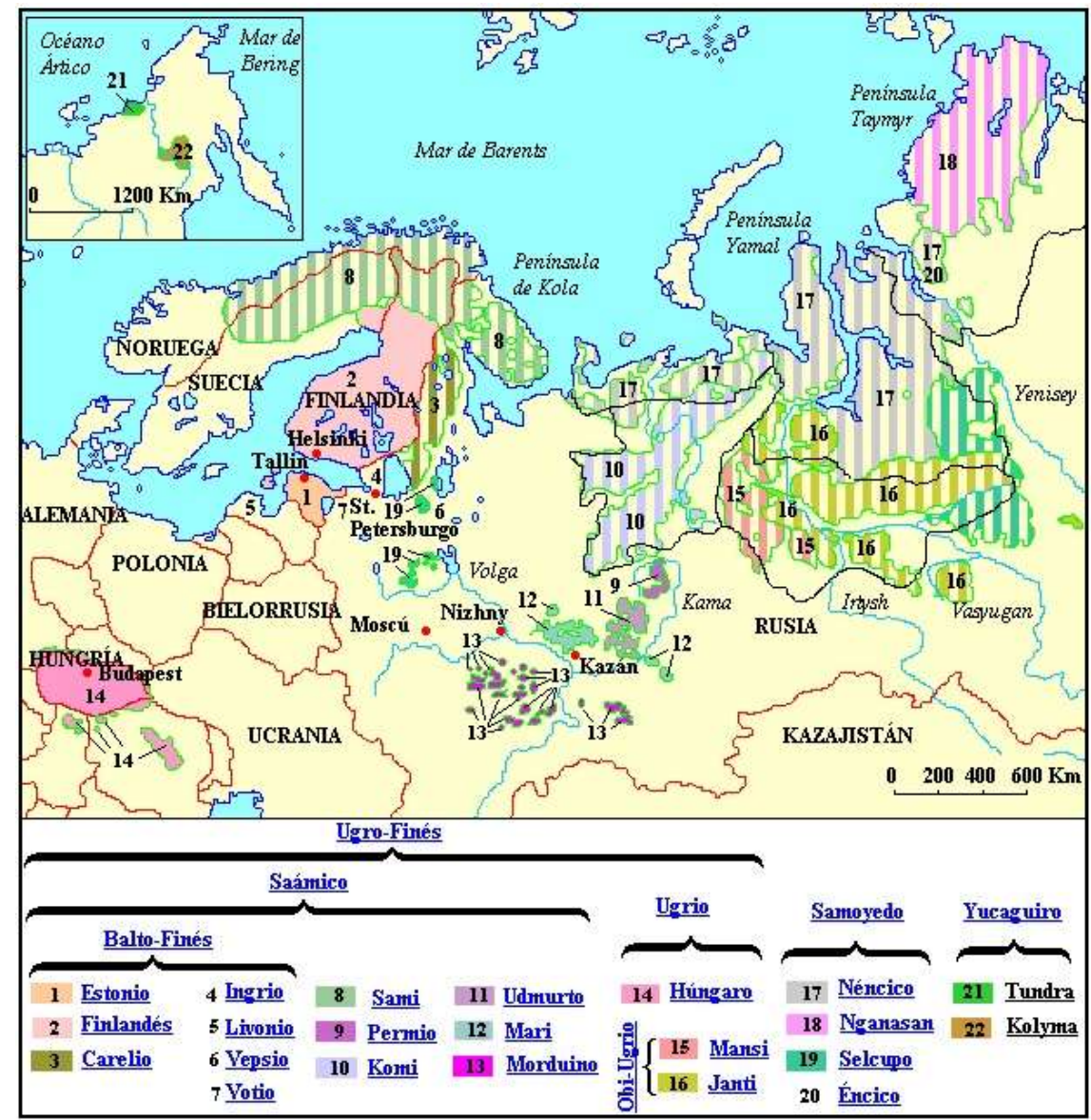

Fuente: $<$ http://www.proel.org/index.php?pagina=mundo/uraloyu/uralo/finougrica $>$

El estonio es hablado por un millón de hablantes aproximadamente. Cuando Estonia consiguió independizarse de Rusia en 1991, el estonio se convirtió en el idioma oficial del país y llegó a ser una lengua oficial de la Unión Europea el 1 de mayo de 2004. El estonio se define como una lengua aglutinante, ya que es una lengua que tiene una estructura morfológica transparente en la que cada morfema que se añade al lexema tiene un único significado. Urmas Sutrop, lingüista estonio, aclara que "Estonian is 
rapidly moving away from agglutination and closer to inflection where each morpheme has several grammatical meanings" (2004:22).

Las principales características del estonio son: (1) la existencia de catorce casos; (2) libertad en el orden sintáctico de la oración; (3) un sistema verbal compuesto por cuatro tiempos, entre los que no se encuentra el futuro; y (4) la ausencia de marca de género gramatical.

Los catorce casos del estonio se clasifican en dos grandes grupos: casos gramaticales y casos semánticos. Sutrop presenta en el siguiente cuadro cómo se organizan estos catorce casos en los dos grupos mencionados, y además traduce las frases estonias a inglés para poder comprender el significado que implica cada caso:

\begin{tabular}{|c|c|c|}
\hline \multicolumn{2}{|l|}{ Case } & Meaning \\
\hline \multicolumn{3}{|c|}{ Grammatical cases } \\
\hline 1. Nominative & ilus tüdruk & (a) beautiful girl \\
\hline 2. Genitive & ilusa tüdruku & $\begin{array}{l}\text { of a beautiful girl; a beautiful girl } \\
\text { (as a total object) }\end{array}$ \\
\hline 3. Partitive & ilusa-t tüdruku-t & a beautiful girl (as a partial object) \\
\hline \multicolumn{3}{|c|}{$\begin{array}{l}\text { Semantic cases } \\
\text { Interior local cases }\end{array}$} \\
\hline 4. Illative & ilusa-sse maja-sse & into a beautiful house \\
\hline 5. Inessive & ilusa-s maja-s & in a beautiful house \\
\hline 6. Elative & ilusa-st maja-st & from a beautiful house \\
\hline \multicolumn{3}{|c|}{ Exterior local cases } \\
\hline 7. Allative & ilusa-le maja-le & onto a beautiful house \\
\hline 8. Adessive & ilusa-I maja-I & on a beautiful house \\
\hline 9. Ablative & ilusa-It maja-It & from on a beautiful house \\
\hline \multicolumn{3}{|l|}{ Other cases } \\
\hline 10. Translative & ilusa-ks tüdruku-ks & [to turn] (in)to a beautiful girl \\
\hline 11. Terminative & ilusa tüdruku-ni & up to a beautiful girl \\
\hline 12. Essive & ilusa tüdruku-na & as a beautiful girl \\
\hline 13. Abessive & ilusa tüdruku-ta & without a beautiful girl \\
\hline 14. Comitative & ilusa tüdruku-ga & with a beautiful girl \\
\hline
\end{tabular}

Fuente: Sutrop (2004:23)

A pesar del gran número de casos que presenta el estonio, se puede observar la falta de un caso acusativo dentro de los casos gramaticales que represente la función de complemento directo del verbo que acompañe. Esta función se suple en estonio con el nominativo, el genitivo o el partitivo.

Como consecuencia de la existencia de esta gran variedad de casos, el orden sintáctico de la oración en estonio es libre pues la relación gramatical entre los 
elementos ya viene marcada por las desinencias y no es necesario que ocupen un lugar específico en la oración para poder establecer las relaciones entre las palabras.

En cuanto al sistema verbal, el estonio cuenta con cuatro tiempos verbales: dos simples (presente y pasado simple) y dos compuestos (pretérito perfecto y pluscuamperfecto). Las tres grandes diferencias entre el sistema verbal estonio y el español son: (1) la falta de un tiempo verbal específico para expresar el futuro, los estonios usan el presente en ese caso; (2) el hecho de que no existe la diferencia entre pretérito indefinido e imperfecto como en español; y (3) la carencia del modo subjuntivo.

La característica que más nos interesa para este trabajo es el hecho de que no existe marca de género gramatical en estonio. Al observar los pronombres personales, podemos comprobar que existen tres formas para el singular y tres para el plural y que se presenta una forma larga y una forma corta, pero no hay en ningún caso diferenciación entre femenino y masculino. De esta manera los pronombres personales son: $1^{\text {a }}$ persona singular, mina/ma; $2^{\mathrm{a}}$ persona singular, sina $/ \mathrm{sa} ; 3^{\mathrm{a}}$ persona singular, temalta; $1^{\mathrm{a}}$ persona plural, meie/me; $2^{\mathrm{a}}$ persona plural, teie/te; y $3^{\mathrm{a}}$ persona plural nemad/nad. Así, por ejemplo, en la frase Ta on minu sõber, ta solo nos indica que se trata de una $3^{\mathrm{a}}$ persona del singular pero no sabemos si es él o ella; por eso si traducimos al español, tenemos dos posibilidades: Él es mi amigo o Ella es mi amiga. Además, como el sustantivo tampoco presenta desinencias específicas de género gramatical, no podemos saber por el resto de componentes de la oración si se está hablando de un hombre o de una mujer. Cuando el contexto no puede ayudar al lector o interlocutor, dependiendo de si se trata de una lectura o de un acto comunicativo, el escritor o hablante introduce la palabra hombre o mujer para aclarar posibles dudas de entendimiento. Por esta razón, entre los errores de los alumnos estonios, que más adelante comentaremos, hemos encontrado un error muy significativo que sirve como ejemplo de esta posibilidad: Liia es morena y alta y guapa mujer. El alumno está describiendo a su compañera y para ello, ha incorporado la palabra mujer para dejar claro el sexo como si los adjetivos morena, alta y guapa no proporcionaran ya dicha información.

El adjetivo solo concuerda en caso y en número con el sustantivo que acompaña, ya que no existe marca de género gramatical. En el ejemplo Tengo un coche rojo y una moto roja, vemos que en la frase en estonio, Mul on punane auto ja punane mootorratas, no existe ninguna diferencia explicita en el adjetivo punane (rojo/a). 
Debido a esta ausencia de marca genérica en el estonio, nos propusimos abordar el análisis de los errores producidos por estos alumnos que tienen que manejar una propiedad lingüística ajena al sistema de su lengua materna.

\section{ANÁLISIS DE ERRORES EN EL GÉNERO GRAMATICAL PRODUCIDOS POR ALUMNOS ESTONIOS}

Los errores que presentamos han sido producidos por un total de 52 alumnos de niveles A1, A2 y B1. Como ya adelantamos, estos errores han sido producidos en diversas actividades que desarrollaban destrezas como la producción escrita (redacciones y descripciones), la interacción escrita (respuesta de cartas y postales), y la expresión escrita (peticiones, respuestas y comentarios).

A la hora de analizar estos errores hemos seguido una clasificación basándonos en criterios morfológicos, léxicos y semánticos. En estas clasificaciones comentaremos el origen de estos errores, veremos cómo los alumnos crean sus propias reglas de formación del género y destacaremos la coincidencia de errores en los diferentes niveles.

\subsection{Análisis y clasificación de errores según criterios morfológicos}

\subsubsection{Sustantivos terminados en $-a$}

Los alumnos se ven afectados por la regla general de que los sustantivos terminados en $-a$ son femeninos, es por eso que encontramos errores con sustantivos inanimados terminados en $-a$. Dada la arbitrariedad del género de los sustantivos inanimados, es necesario comprender que los alumnos se muestran confusos y crean sus propias relaciones entre las terminaciones y el género.

Estos errores han sido cometidos por alumnos de A2 y de B1. Los errores de A2 son: $Y$ ¿que tu *esta haciendo estas días?; Hay una lámpara a la izquierda de la sofá; Hay una lámpara a la derecha de la sofá; Hay una lámpara al lado de la sofá. En estos tres últimos ejemplos, los alumnos tenían que completar los huecos con la preposición de lugar adecuada teniendo en cuenta la imagen del ejercicio. Por otro lado, en las frases producidas por alumnos de B1 notamos un mejor dominio de la gramática y variedad en el léxico pero el problema con el género sigue presente y acaban cometiendo los mismos errores que los alumnos de niveles inferiores: ¡Tenemos que contener nuestra planeta de basura! ;Gracias por su colaboración!; *Llamame, por favor, *quando 
*sabrás la día *del operación. En este último ejemplo notamos además otro error de género, pero será comentado más adelante.

\subsubsection{Sustantivos terminados en -e}

Cuando los alumnos deben usar sustantivos cuya terminación morfológica es $-e$ o - es, ya sean sustantivos inanimados o animados, los alumnos tienden al uso del masculino. Asocian la terminación $-e$ como marca genérica del masculino. En el caso de sustantivos inanimados, hemos encontrado tanto sustantivos concretos como abstractos en los errores producidos por los alumnos: Yo *tiene vacaciones pequeño; Pedro tiene 3 habitaciones, pero Juan sólo uno; La *Juan casa no hay tantos habitaciones como la *Pedro casa; Me llevo bien con Anne, porque ella es divertida en los clases de español; En *algos lugares tuvimos el nieve; Entonces los frases en español son:...; Yo salí ayer y el tarde fue muy largo.

En estos ejemplos hay que observar el hecho de que los alumnos mantienen la concordancia aunque confundan el género de los sustantivos y, por ende, elijan mal el de los artículos o de los cuantificadores que los acompañan: tantos habitaciones, los clases, el nieve, etc.; incluso hasta cuando la concordancia se da entre tres términos: el tarde fue muy largo. Es importante destacar que estos errores se han producido en el nivel A2, pero también contamos con errores de nivel B1 en el caso de usar sustantivos inanimados terminados en -e o en -es: Este verano he nadado pocos veces en el mar; Me molesta televisión, por eso no tengo el tele; Me interesan los *elexiones del gobierno; Muchos cruceros salen de Ushuaia y yo *tambien fui a un crucero *ronda del Cabo de Hornos y dentro *un *monton de islas, que forman, en verdad, un parte de Chile y donde por ejemplo Charles Darwin ha trabajado; He *recogido unos clases de tango argentino, clases individuales; Durante los meses de verano tenemos algunos dificultades con agua por eso * pedimos a ustedes * ayudarnos * ahorrarlo. Si necesitan regar los flores, pedimos regarlos por la mañana muy temprano o por la noche muy tarde. En los ejemplos de B1 vemos cuán importante es el buen uso de la marca de género, ya que a la hora de usar pronombres átonos de complemento directo, el alumno necesita saber el género del sustantivo que sustituye para la correcta elección del pronombre. A pesar de que hacen una elección errónea del género, como ya hemos visto también en los ejemplos anteriores, los alumnos mantienen la concordancia: $\mathrm{Si}$ necesitan regar los flores, pedimos regarlos... 
En el caso de los sustantivos animados, los alumnos también tratan los sustantivos terminados en $-e$ como masculino sin tener en cuenta que son sustantivos comunes en cuanto al género: Tuve un paciente de Cuba, que era interesante. Este paciente fue una cubana, estaba casada con un chico de Finlandia. Es curioso que el alumno, de nivel A2, está hablando sobre una mujer cubana y aun así usa la forma masculina al usar el sustantivo paciente estableciendo una concordancia entre el supuesto género masculino de los sustantivos terminados en $-e$ y los determinantes. Esas dudas con respecto a esta terminación llevan al alumno al error incluso cuando conocen que el término designa a una persona de sexo biológico femenino: El padre está durmiendo. El madre está leyendo el periódico.

\subsubsection{Sustantivos terminados en $-o$}

Como en el caso de los sustantivos terminados en $-a$, los alumnos se centran en la regla general y tratan como masculinos los siguientes sustantivos inanimados femeninos: Todos escucharon el radio con padres y hermanos; ;Tengo muchos fotos y *quería hablar más cuando *encontraremos! Estos sustantivos, radio y foto se consideran acortamientos de palabras femeninas cuyas formas completas son: radiodifusión y fotografía. Los dos errores que recogemos en este apartado han sido cometidos por dos alumnos de nivel B1.

\subsubsection{Sustantivos terminados en consonante}

Al encontrarse con sustantivos acabados en consonante, los alumnos de los tres niveles (A1, A2 y B1) prefieren la forma masculina ante la femenina. En este caso se trata de sustantivos inanimados que terminan en -ción: El español es el *aficion para ella; Tengo que ir en un *operacion en 30 minutos; También espero que el operación de tu rodilla vaya bien y que puedas jugar el fútbol de nuevo; Llamame, por favor, quando *sabrás *la día del operación; Si necesitas un *traducion, escríbeme; en -l: El capital de Ecuador es Quito; en -sión: Me molestan las pausas entre las películas por el televisión; No se como es en español esto expresión; y en -z: ¡Vi pingüinos! El primero vez de mi vida; Perdon mama, esto es lo *ultimo vez.

De los ejemplos esto expresión y esto es lo *ultimo vez es importante destacar el uso de esto y de lo, que han sido ejemplos producidos por el mismo estudiante de nivel A2. El alumno le asigna al demostrativo y al artículo definido masculino singular la terminación mayoritaria para designar el género masculino: -o. Esto y lo son formas que 
ya ha visto en su proceso de aprendizaje pero no las ha asimilado bien y por eso, ha desechado de su interlengua las formas este y el. Este caso nos hace ver que la enseñanza y el aprendizaje del género deben tener mayor relevancia para evitar problemas en la producción del alumno y no dejar al alumno caer en la idea general de que la $-o$ es la marca de género masculino.

\subsubsection{Concordancia con términos cercanos}

Debido al distanciamiento del referente, los alumnos se ven un poco perdidos pues no tienen la referencia cerca y eligen, en estos casos, una forma masculina de los adjetivos dejándose llevar por un sentido de concordancia que establecen con la palabra inmediatamente anterior: en ambos casos el cuantificador poco. Los alumnos, de nivel A1 y A2, deciden añadir el morfema - $O$ al adjetivo serioso para estar de acuerdo con el cuantificador. Este adjetivo es una adaptación del adjetivo serious del inglés: Jaava tiene 30 y mas años y es *hica muy activa pero un poco serioso; Ella es muy inteligente y un poco serioso.

\subsubsection{Alteraciones en la morfología de las palabras para mantener la concordancia}

Hemos encontrado una serie de alteraciones o cambios morfológicos en ciertas palabras que los alumnos de nivel A1 y A2 llevan a cabo debido a la existencia de la concordancia. En los siguientes ejemplos, los alumnos han cambiado la morfología de la forma verbal para concordar con el sustantivo. En "Este bolso verde, ¿Cuánto questo? Perdone, ¿cuanto *questa esta?" la alumna cambia la terminación del verbo costar para hacer concordar en género con el sujeto como si se tratase de un adjetivo y no de una forma verbal personal. El hecho de que la tercera persona singular del presente de indicativo de los verbos de la primera conjugación sea $-a$, coincidiendo con la terminación general de los sustantivos femeninos, llevan a los alumnos al error de fusionar las dos terminaciones y cambiar el verbo: *questo. Un mismo alumno ha producido las siguientes preguntas: ¿Cuánto cuesta la mochila? ¿Cuánto cuesto el abrigo? ¿Cuánto cuestas las gafas de sol? ¿Cuánto cuestos los pendientes? Estos ejemplos evidencian claramente que los alumnos tienen en mente el fenómeno de la concordancia y que saben que existe alguna relación entre el verbo y el sustantivo posterior. 
No solo hemos encontrado estas alteraciones en verbos personales, también en las formas no personales de gerundio y participio. En La abuela está vienda la tele. La madre está leyendo el periódico, podemos observar que el alumno establece una relación de concordancia entre el gerundio y el sustantivo siguiente cuya función es la de núcleo del sintagma nominal que funciona como complemento directo. En ¿Ellas han comida paella alguna vez? Sergio ha estado en España nunca, ocurre lo mismo pero en este caso con el participio.

Entre los errores también hemos encontrado cambios morfológicos del sustantivo manteniendo la concordancia de una marca de género errónea: Belen esta escribiendo la correa; El abuelo esta jugando a los cartos. Otros cambios se producen en el sustantivo o adjetivo suprimiendo morfemas finales para conseguir la terminación idónea para el género deseado: *Me mejor amigo es *person muy interesante; ¿Me puedes dejar tu coche? No, es que no tengo dinero por el *gasolin.

En este apartado incluimos también una serie de errores producidos por los alumnos de nivel A1 en un ejercicio sobre las profesiones. Los alumnos iniciales se basan en las reglas generales de masculino y femenino. Debido a esto, los alumnos modifican los sustantivos comunes terminados en -ista y en -ante. Por ejemplo: Ella es *studienta; Ella es *studenta; El es cantaro; El es periodisto; El es futbolisto. En los dos primeros errores, los alumnos se ven influenciados por el sustantivo inglés student y es a este lexema al que le añaden la terminación $-a$, generalmente femenina, para referirse a ella. En el tercer ejemplo, el alumno añade el morfema $-o$, mayoritariamente masculino, al lexema cantar para designar a la persona que se dedica profesionalmente a cantar. Con respecto a los dos últimos errores, los alumnos han decidido cambiar la terminación -ista en -isto ya que ambos tienen un referente masculino. Es importante comentar que de los veintinueve alumnos de A1 que realizaron este ejercicio: ocho escribieron Él es futbolisto; seis decidieron cambiar el pronombre personal aunque en el dibujo se veía claramente que se trataba de un chico y no de una chica, Ella es futbolista; tres solo escribieron la profesión sin usar el pronombre personal y solo diez no presentaron ningún error. Esto indica que ya desde niveles iniciales existe una tendencia a relacionar de manera exclusiva el morfema $-o$ con el masculino y el morfema $-a$ con el femenino y que se necesita más tiempo y dedicación por parte de los profesores a tratar errores de este tipo para que los alumnos empiecen a comprender que existen otras clases de género. 


\subsubsection{Aciertos}

No solo queríamos analizar los errores sino también un par de aciertos de los alumnos de nivel A2 que nos han parecido dignos de mención. El primero es la correcta elección del morfema -o para calificar un hecho completo: Esta postal es *ultima parte de test. ¿Muy extraño, *sabeis? Uno de los pocos casos en los que el neutro está presente en la gramática del español es cuando calificamos una oración o usamos un pronombre para hacer referencia a ella.

El segundo acierto es la correcta elección del femenino para calificar una ciudad cuyo nombre termina en $-a$ y del masculino cuando termina en otra vocal o en consonante: *Voy a Barcelona la semana pasada. Estaba muy bonita!; Granada es *muy bonita ciudad!; Creo que Granada es *bonissima; ;Amsterdam es bonito!

\subsection{Análisis y clasificación de errores según criterios léxicos}

Al usar una palabra que puede ser tanto determinante como adverbio, participio o adjetivo, los alumnos usan la forma que conocen más. En estos ejemplos Esta haciendo mucho cosas importantes; Aqui el tiempo ha sido muy bien 10-15 grados y mucho lluvia; Bebi mucho cerveza de Saaremaa, tienes que probar; y Me molesta estar en la prensa y ganar mucho publicidad, los alumnos utilizan la forma de adverbio invariable mucho como única forma incluso cuando se trata de un cuantificador. Lo mismo ocurre en el siguiente ejemplo con el uso del participio como adjetivo: Esto es un anglicismo, una palabra prestado. También encontramos el mismo tipo de error cuando se trata del cuantificador todo: Estoy trabajando mucho también. Es que tengo que cerrar todo cosas de trabajo.

Algo similar ocurre cuando el alumno tiene que usar los adjetivos demostrativos. En los siguientes ejemplos, los alumnos no concuerdan el adjetivo demostrativo con el sustantivo que acompañan, como si este se tratase de una palabra invariable que solo presenta la forma este: Es que yo trabajé mucho este semana; En este semana es *ultima clase de español; Este semana estoy trabajando mal; En este semana yo he visitado Córdoba tambien y en la semana pasada *viaja a Patagonia; Este nota está escrito para informarle de las normas como usar los recursos en este campin. En este caso encontramos errores comunes que se producen en los niveles A2 y B1. 


\subsection{Análisis y clasificación de errores según criterios semánticos}

\subsubsection{Concordancia ad sensum}

La concordancia ad sensum consiste en un fenómeno según el cual la concordancia que se establece entre los elementos de un sintagma se basa en una concordancia semántica y no morfológica. Este fenómeno hace que los alumnos produzcan errores al elegir el género en relación al sexo del ser designado para concordar con este y no con el sustantivo elegido.

Algunos ejemplos de nivel A2 son: *El es muy bueno persona y Natalja *tienes pelo liso y morena. En la primera frase, el alumno está describiendo a un hombre y por eso, concuerda el adjetivo bueno con el referente en lugar de con persona. El alumno desconoce que el sustantivo persona es un nombre epiceno y por tanto, tiene la misma forma en caso de un referente masculino o femenino. Como ya hemos visto en otros casos, ha asociado la terminación en $-a$ con femenino y piensa que si utiliza buena está describiendo a una mujer. En el segundo ejemplo, el alumno ha cometido un error que puede ser interpretado de dos maneras: (1) el alumno ha olvidado introducir el verbo ser: Natalia tiene el pelo liso y es morena; (2) el alumno ha concordado morena con su referente dejándose llevar por la concordancia ad sensum y no con el sustantivo pelo.

\subsubsection{Concordancia con el hiperónimo de la clase léxica}

En los ejemplos siguientes hemos notado que los alumnos se han dejado llevar por un criterio semántico, ya que se basan en el género del hiperónimo de la clase léxica a la que pertenece el sustantivo que han elegido para concordar los artículos o adjetivos que están relacionados con él. Como ya comentamos anteriormente, el género de algunos sustantivos inanimados depende del hiperónimo de la clase léxica a la que pertenecen; de esta manera, tres alumnos de nivel A2 eligieron el masculino para determinar una Coca-Cola teniendo en cuenta que el hiperónimo es refresco: ¿Me puede dar un Coca Cola?; ¿Me pone un Coca Cola por favor?; ¿* Puedes dar un *cola por favor? En este caso no podemos calificarlo estrictamente como un error, ya que, de hecho, hay zonas en el sur de España donde se utiliza el masculino al referirse a Coca-Cola o a Fanta. Debido al alto nivel de uso al referirse a estas marcas, estos nombres propios no personales se han lexicalizado, lo que implica su incorporación al léxico con sus propias características gramaticales de género y número. Por eso, en la mayoría de las zonas hispanohablantes se consideran sustantivos femeninos. 
Lo mismo ocurre en el siguiente ejemplo en el que el alumno, también de nivel A2, elige el masculino para referirse a un monumento: En Granada *es muy grande y grandioso Alhambra. Al igual que en los ejemplos anteriores, el sustantivo usado termina en $-a$ pero los alumnos no hacen la relación del género de manera morfológica, basándose en la terminación del sustantivo elegido, sino de manera semántica, teniendo como referencia el género del hiperónimo del grupo léxico al que pertenecen dichos nombres propios no personales. La diferencia con los ejemplos anteriores es que en este caso el uso del masculino sí es considerado un error.

\subsubsection{Concordancia con el referente cultural}

Hemos encontrado dos errores con el mismo sustantivo producidos por diferentes alumnos. Los alumnos han utilizado el sustantivo vestido en una forma femenina. Esta elección se puede deber a que han establecido una relación sociocultural entre la prenda y el sexo biológico de la persona que la usa. Como vestido es una prenda únicamente femenina, los alumnos de nivel A2 utilizan la palabra en femenino y así concuerdan el artículo y el adjetivo que la acompañan en el sintagma nominal: Hoy llevo una vestida gris y *jacketa verde, muy bonita; ; $Y$ *que bonitas vestidas estoy comprando!

\subsection{Variabilidad libre en la interlengua}

Entre los errores recogidos encontramos algunos que no se producen sistemáticamente y que su clasificación en uno de los apartados anteriores es difícil, puesto que no se corresponden con ninguno y sobre todo, presentan una notable variabilidad. Así bien, Ellis (1992) clasifica la variabilidad de la interlengua en dos grandes grupos: variabilidad sistemática y variabilidad no sistemática. Es este último grupo el que nos interesa en este apartado, ya que los errores que presentamos no son producidos por sistema sino de forma aleatoria.

Siguiendo con la clasificación que plantea Ellis (1992), la variabilidad no sistemática, a su vez, se divide en variabilidad en la actuación y variabilidad libre. La variabilidad en la actuación consiste en la producción de algún fallo en el momento de la actuación del aprendiente, como un lapsus o desliz, o un falso comienzo. Son errores o fallos fácilmente corregibles por el propio aprendiente. Por otro lado, la variabilidad libre se refiere al fenómeno en el que el aprendiente posee dos o más formas, que usa para realizar la misma variedad de significados. Es el resultado de reglas conflictivas en la competencia del aprendiente. 
La interlengua está marcada por un alto nivel de variabilidad libre, una característica que es importante para explicar cómo la interlengua evoluciona. Según Ellis (1985) la adquisición de una segunda lengua conlleva dos etapas: (1) la asimilación de nuevas formas, y (2) la organización de las correlaciones entre forma y función. La variación no sistemática se produce cuando se asimilan nuevas formas, pero aún no se han integrado en el sistema de forma-función del alumno. En las fases posteriores el alumno va clasificando de manera progresiva las formas en relación con la función que desempeñen. Este proceso de clasificación es continuo siempre y cuando se asimilan nuevas formas, ya que cada nueva forma conllevará necesariamente una reorganización funcional adicional. De este modo, la variación sistemática se empieza a producir cuando las nuevas formas han sido alojadas por el sistema de forma-función ya existente.

Como ejemplos de esta variabilidad libre en la interlengua, hemos encontrado una serie de errores en los que los alumnos muestran esa inconsistencia en el uso del género y reflejan sus dudas sobre esta cuestión gramatical. En los siguientes ejemplos de niveles A1 y A2, los alumnos concuerdan de manera perfecta la mayoría de los adjetivos que usan para describir a una compañera, pero cometen errores incomprensibles que hacen tambalear la percepción de una buena adquisición del género: Ella es guapa, morena. Lleva camisa negro, pantalones. Tiene el pelo largo, *risado. Tiene los *ochos oscuras. Lleva gafas. Otros ejemplos son: Jaava lleva jersey azul y pantalones azul también y los botas; El abuelo *esta jugando del cartas; Raquel *esta hablando por la telefono; (Natalja) *Se es muy tranquilo y trabajadora; *Despues está comprando una *bueno vestido y camisa; Mi amigo se llama Karina. Ella vive en Oru. Ella es rubio y un poco bajo. De todos estos ejemplos, vamos a comentar los tres últimos para destacar algunos aspectos curiosos o llamativos.

En el primero de estos tres ejemplos últimos, el alumno comete dos errores al describir a su compañera Natalja: *Se es muy tranquilo y trabajadora. El primer error es un error bastante común que he podido reconocer en varios de los alumnos estonios: el uso de se en lugar del pronombre personal ella. Creemos que este uso se debe a una errónea asociación entre el pronombre de tercera persona del singular (él/ella) con la forma pronominal se de los verbos como levantarse, ducharse, acostarse, etc. Y el segundo error, es un error de concordancia que solo se produce con el adjetivo tranquilo pero no con el adjetivo trabajadora. 
En el segundo ejemplo, *Despues está comprando una *bueno vestido y camisa, el alumno mantiene la concordancia con el adjetivo inmediatamente anterior al sustantivo pero no con el artículo indefinido, el cuál sí concuerda con el sustantivo camisa del final de la frase.

Y, por último, en el tercer ejemplo, Mi amigo se llama Karina. Ella vive en Oru. Ella es rubio y un poco bajo, el alumno solo mantiene la concordancia con el pronombre personal sujeto de tercera persona del singular ella al referirse a Karina pero en el resto de la frase no observamos ninguna concordancia entre el referente (Karina) y el sustantivo amigo, ni en los adjetivos calificativos rubio y bajo, como también ocurre en otro ejemplo de otro alumno: Liia es morena y alta y guapa mujer. Ella es muy simpático.

Otro grupo de errores pertenecientes a este último apartado es el formado por los siguientes enunciados de alumnas de nivel A2 y B1 en los que estas hablan de sí mismas en masculino: Es que ayer *estoy cansado; Estoy muy sorprendido por los resultados; Este mes he estado muy ocupado. Es curioso que se produzcan este tipo de errores cuando ellas están hablando sobre sí mismas y, evidentemente, tienen presente su sexo biológico.

\section{PROPUESTA DE ACTIVIDADES DIDÁCTICAS}

Aunque como hemos explicado en el apartado 2.3.1., el Plan Curricular del Instituto Cervantes (2007) recomienda la introducción de la enseñanza de sustantivos epicenos y ambiguos en niveles $\mathrm{B} 1$ y $\mathrm{C} 1$ respectivamente, entendemos que esta recomendación está hecha para una enseñanza del español desde un punto de vista general. Por tanto, hemos decidido en nuestro caso particular con alumnos estonios empezar a introducir este tipo de sustantivos en un nivel A2 para atender así las necesidades específicas de este perfil de alumnos. Además, creemos que de no hacerlo en un nivel básico, se puede lamentar más adelante pues los alumnos tienden a la fosilización en este campo determinado.

Nuestra idea es, a tenor de algunos de los datos e ideas consideradas hasta ahora, presentar aquí algunas sugerencias (que planteamos aquí solo pergeñadas) de una serie de actividades relacionadas con el género para un nivel A2. En esta secuencia queremos que los alumnos se centren en las formas de los sustantivos y sean capaces de entender y de analizar el funcionamiento del género gramatical. Tras haber analizado los errores de los alumnos estonios, hemos usado tales errores para la creación de esta secuencia 
didáctica. La secuencia consiste en cinco actividades que los alumnos pueden realizar de manera individual para un estudio reflexivo y comprensivo de las formas y de las implicaciones semánticas de dichas formas.

La primera actividad consiste en una actividad donde el alumno tiene que identificar el intruso de un grupo de palabras. Es una actividad muy útil pues los alumnos buscan los rasgos comunes que tienen esas palabras para poder descartar aquella que no los cumple. Es una actividad analítica y reflexiva que ayuda al alumno en el aprendizaje del género gramatical. Algunos grupos de palabras pueden ser los siguientes: cama - problema - crema - fama; cuaderno - bolígrafo - mano - bolso; oasis - crisis - hipótesis - tesis; estación - canción - televisión - avión; humor - sudor - olor - flor; paz - lápiz - voz - nariz. De esta manera, los alumnos entienden que la misma terminación puede ser marca de género masculino o femenino y que existen excepciones a las reglas generales. Estaría bien si los alumnos usan el diccionario en esta actividad para buscar el género de cada palabra, así no solo conocen el género sino que también aprenden a usar el diccionario.

La segunda actividad trata de una actividad de concordancias. Para este ejercicio vamos a contar con la canción Bonito de Jarabe de Palo. En esta canción se habla de lo bonitas que son muchas cosas. El alumno tiene que concordar el adjetivo bonito con una serie de sustantivos que aparecen en la letra de la canción. Algunos de los sustantivos de la canción son: lugar, día, amor, fin de semana, mañana, vida, paz, amistad, gente, etc. Entre los sustantivos de la canción se encuentra el sustantivo ambiguo mar y además aparece tanto acompañado por el artículo determinado masculino como por el femenino. Puede ser una buena manera de presentar al alumno este tipo de sustantivos. La actividad puede terminar con la audición de la canción para corregir el ejercicio.

La tercera actividad consiste en una comprensión lectora. Los alumnos tienen que leer las biografías de personas famosas del mundo hispanohablante y decidir de quién se está hablando. Deben leer con atención las descripciones dadas pues hay pistas que les indican de quién se trata. La dificultad reside en el hecho de que los sustantivos que aparecen en las descripciones presentan una formación anómala. Todos los sustantivos que se refieren un famoso terminan en $-O$, y todos los referidos a una famosa terminan en $-a$. El alumno notará que algo extraño está pasando cuando empiece a leer las biografías. La finalidad de este ejercicio es doble: por un lado, tienen que comprender el texto para averiguar de qué famoso se trata y por otro lado, tienen que darse cuenta y corregir aquellas formas sustantivas que presentan otra terminación 
que no se corresponde con la regla general. De esta manera, se pretende también que el alumno sea consciente de la molestia que siente un nativo cuando se producen errores de este tipo. Un ejemplo de estas biografías puede ser: nació en Málaga el 25 de octubre de 1881. Fue un pintoro, escultoro españolo y uno de los creadoros del cubismo. Es considerado uno de los mayoros pintoros del siglo XX. Influyó en otros grandos artistos de su tiempo. Los alumnos tienen pistas suficientes para saber de quién se trata. En este caso, el alumno comprenderá que también hay sustantivos acabados en -or y que hay palabras comunes a ambos géneros como artista. Otro ejemplo de estas biografias, en este caso sobre una famosa, puede ser esta: nació en Costa Rica el 17 de abril de 1919, pero durante su juventud se fue a vivir en México. Fue una cantanta y actora. Es considerada una de las figuras principalas de la música ranchera.

La cuarta actividad consiste en una actividad de reflexión gramatical. Los alumnos tienen que relacionar los sustantivos de unas frases con los siguientes nombres propios de persona: José, María, Pablo y Lola, Lola y María, José y Pablo. Los sustantivos de las frases son sustantivos de todos los tipos: masculino, femenino, epiceno y común. En esta actividad también se tiene en cuenta el número de los sustantivos, para que así los alumnos empiecen a entender el uso del masculino genérico. Con ello, los alumnos tienen que reflexionar sobre la forma que presenta el sustantivo y con qué nombre propio se puede relacionar. En el enunciado se aclara que hay más de una posibilidad y que deben seleccionar todos los nombres posibles. Por ejemplo: La persona herida en el accidente de ayer ha abandonado el hospital esta tarde. Las profesoras de este instituto están de huelga por motivos de discriminación. Los ciudadanos de este país están luchando por sus derechos. El personaje principal de la obra vive en un barrio rico de Londres. Han sido víctimas de una broma de mal gusto. Tras la realización de esta actividad, el alumno será más consciente de que ciertos sustantivos que designan a personas de ambos sexos pueden presentar una misma forma.

La quinta actividad consiste en una actividad de corrección. Algunas de las frases de la actividad presentan errores que pueden ser errores tanto de concordancia como de elección de género gramatical. El alumno tiene que ser capaz de localizar el error y de corregirlo. Para que la actividad sea más completa, el alumno tiene que explicar por qué es un error y por qué se da lugar a errores de ese tipo. Para esta actividad el alumno tiene que recurrir a gramáticas especiales para alumnos extranjeros ya que tienen que aportar una explicación gramatical. De esta manera el alumno presta 
más atención a las formas y se acerca de una manera más analítica a la lengua. Algunas de las frases de esta actividad pueden ser: Las jirafas machas pueden medir aproximadamente cinco metros. El futbolisto marcó cuatro goles en la partido de ayer. La mapa está equivocado porque este museo no está en este calle. El toro hembra ha tenido cuatro terneros este mañana. El operación de esta paciente fue un poco arriesgado debido a su avanzada edad. Ahora uso el moto de mi padre para ir al trabajo a causa del trafico tan espantosa.

\section{CONCLUSIONES}

En este último apartado del trabajo presentamos las ideas principales surgidas al analizar los errores, comentamos nuestras limitaciones y presentamos futuras líneas de investigación a partir de este trabajo de fin de máster.

Tras el análisis de los errores cometidos por alumnos estonios, las conclusiones que sacamos son las siguientes: (1) los alumnos prefieren el uso del masculino como el género defectivo; (2) los alumnos producen más errores cuando el referente del sustantivo es inanimado; (3) los alumnos mantienen la concordancia entre los elementos del sintagma a pesar de que el género sea erróneo.

Como ya comentamos en el apartado 2.2., los alumnos utilizan el masculino como género por defecto. En la siguiente gráfica, podemos observar que el $74 \%$ de los errores recogidos en este trabajo, son errores en los que el alumno ha utilizado el masculino en lugar del femenino, mientras que solo un $17 \%$ de los errores son por preferencia del femenino sobre el masculino. El 9\% hace referencia a los casos de variabilidad recogidos en este trabajo.

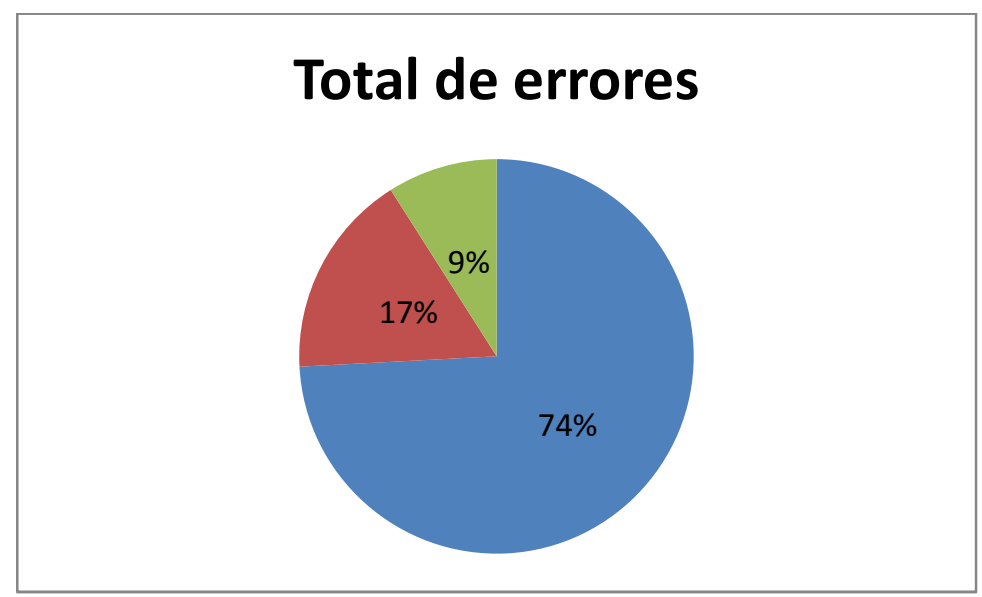


Hemos contabilizado los sustantivos que los alumnos han utilizado en sus frases y podemos comprobar en la siguiente gráfica que el $78 \%$ de los errores cuenta con sustantivos inanimados, mientras que en el $22 \%$ restante encontramos sustantivos animados. Es lógico que el uso de sustantivos inanimados tenga más probabilidad de error ya que el alumno no cuenta con el sexo del referente como pista fiable a la hora de elegir el género. De ese $22 \%$ donde los alumnos han usado sustantivos animados, el $17 \%$ son sustantivos comunes en cuanto al género y el $5 \%$ representa el uso de otros sustantivos animados. Por otro lado, también es lógico que dentro de los sustantivos animados, aquellos que presentan mayor dificultad para su asimilación y adquisición sean los sustantivos comunes en cuanto al género ya que el alumno tiende a la variación $-o /-a$.

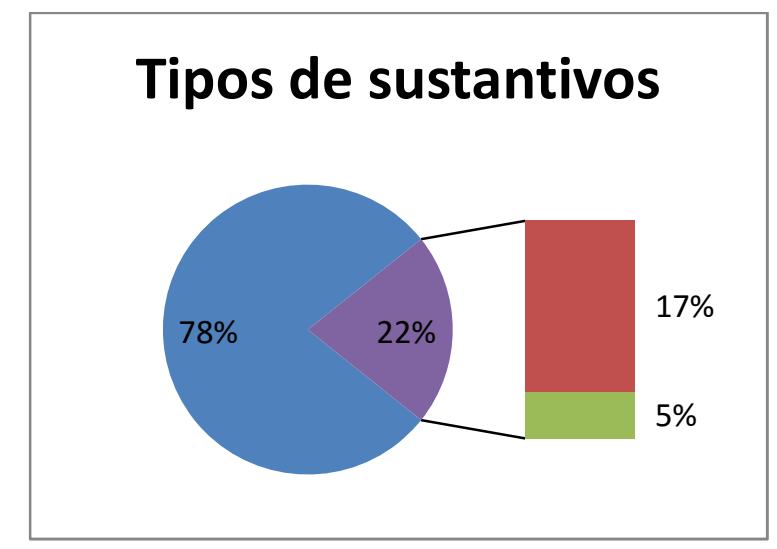

La última conclusión hace referencia al fenómeno de la concordancia. Los alumnos mantienen la concordancia en el $70 \%$ de los casos recogidos aunque el género concordado sea erróneo. De ese $70 \%$ hay que destacar que el $40 \%$ se corresponde con los casos en los que los alumnos modifican los complementos que se refieren al sustantivo para concordarlos con el supuesto género de este. En la mayoría de los casos se trata de determinantes artículos, pero también se encuentran casos de adjetivos. El $20 \%$ de los errores concordados representa los casos en los que los alumnos han modificado la morfología del sustantivo para hacerlo concordar con el referente. El 8\% y $2 \%$ restantes hacen referencia a los casos de concordancia del sustantivo con formas verbales y a casos de concordancia ad sensum respectivamente. Como podemos observar, solo un $30 \%$ de los casos muestra una falta de concordancia. 


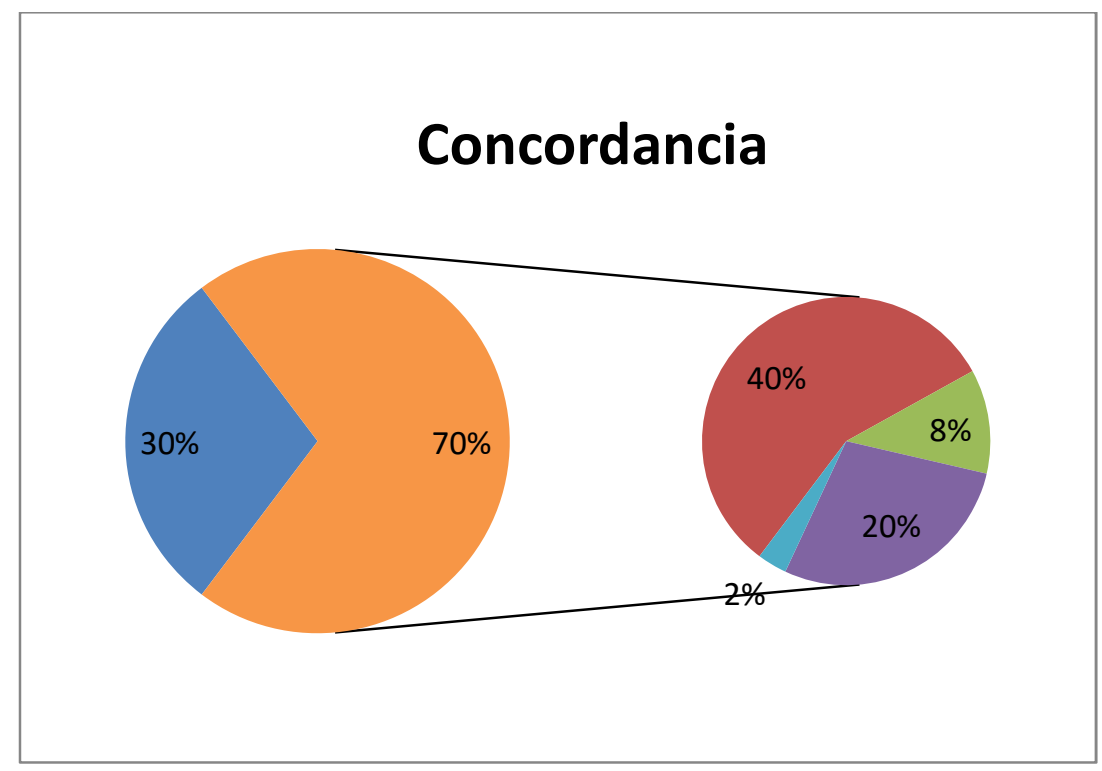

Es necesario comentar las limitaciones de este trabajo. Los errores presentados han sido producidos con una serie de actividades diversas que no estaban enfocadas a un buen uso del género gramatical por parte de los alumnos, solo una de las actividades de nivel A1 tenía el objetivo de comprobar si el alumno había asimilado bien el género gramatical en el uso de las profesiones. Las otras actividades han sido actividades pensadas con otros objetivos gramaticales y pragmáticos. Fue por la gran cantidad de errores encontrados sobre el género, que decidimos desarrollar este trabajo de fin de máster. Por eso, este trabajo no consiste en una investigación con un grupo de control y un grupo experimental. Los alumnos solo comparten la nacionalidad estonia pero no hemos seleccionado y clasificado a estos alumnos según variables que podrían ser relevantes. Por ejemplo, habría sido conveniente saber si algún alumno tenía conocimiento de algún otro idioma del tronco indoeuropeo aparte del español.

Por último, como futuras líneas de investigación planteamos el uso de nuestra serie de actividades como apoyo docente en las clases de español para compensar la falta de actividades especificas de género en los manuales. De esta manera se puede comprobar si los alumnos adquieren mejor este rasgo gramatical con actividades de atención a la forma. También se podría presentar un trabajo de investigación teniendo en cuenta las clasificaciones de errores presentadas en este trabajo para comprobar si dichas clasificaciones se repiten con otros alumnos que no tengan género en su lengua materna, o incluso, también sería un interesante trabajo de investigación uno basado en la comparación entre alumnos que sí tienen género gramatical en su lengua materna y los que no a la hora de aprender y adquirir el género gramatical en español. 


\section{BIBLIOGRAFÍA}

ALARCÓN, I. (2006). The Second Language Acquisition of Spanish Gender Agreement: The Effects of Linguistic Variables on Accuracy. Munich: LINCOM Europa.

- (2010). "Gender Assignment and Agreement in L2 Spanish: The Effects of Morphological Marking, Animacy, and Gender", Studies in Hispanic and Lusophone Linguistics 3 (2): 267-299.

--------- (2011). "Spanish Grammatical Gender under Complete and Incomplete Acquisition: Early and Late Bilinguals' Linguistic Behavior with the Noun Phrase”, Bilingualism: Language and Cognition 14 (3): 332-350.

(2014). “Grammatical Gender in Second Language Spanish", en K. L. GEESLIN, The Handbook of Spanish Second Language Acquisition. Malden, MA: Wiley-Blackwell.

ALONSO RAYA, R., CASTAÑEDA CASTRO, A., MARTíNEZ GILA, P., MIQUEL LÓPEZ, L., ORTEGA OLIVARES, J., RUIZ CAMPILLO, J.P. (2005). Gramática Básica del Estudiante de Español. Barcelona: Difusión (2 $2^{\mathrm{a}}$ edición revisada y aumentada: 2010).

ARAGONÉS, L. Y PALENCIA, R. (2008). Gramática de Uso del Español. Teoría y práctica. Madrid: SM.

BATES, E. y MacWHINNEY, B. (1987). "Competition, Variation, and Language Learning”, Mechanisms of Language Acquisition: 157-193.

CORPAS, J., GARCÍA, E. y GARMENDIA, A. (2013). Aula Internacional 1 Nueva Edición. Barcelona: Difusión.

CORPAS, J., GARMENDIA, A. y SORIANO, C. (2005). Aula Internacional 2. Barcelona: Difusión. 
ELLIS, R. (1985). "Sources of variability in interlanguage", Applied Linguistics 6, 2: 118-131.

(1992). "Learning to Communicate in the Classroom: a Study of Two Learners' Re-quest", Studies in Second Language Acquisition 14: 1-23.

FRANCESCHINA, F. (2005). Fossilized Second Language Grammars: The Acquisition of Grammatical Gender. Amsterdam: John Benjamins.

HAWKINS, R. y CHAN, Y. (1997). "The Partial Availability of Universal Grammar in Second Language Acquisition: the "Failed Functional Features Hypothesis"”, Second Language Research 13: 187-226.

KEATING, G. D. (2009). "Sensitivity to Violations of Gender Agreement in Native and Nonnative Spanish: An Eye-Movement Investigation”, Language Learning 59 (3): 503-535.

LOZANO ZAHONERO, M. (2010). Gramática de Referencia de la Lengua Española. Milano: Ulrico Hoepli Editore.

PÉREZ-PEREIRA, M. (1991). “The Acquisition of Gender: What Spanish Children Tell Us", Journal of Child Language 18 (3): 571-590.

PRÉVOST, P. y WHITE L. (2000). "Missing Surface Inflection or Impairment in Second Language Acquisition?: Evidence from Tense and Agreement", Second Language Research 16 (2): 103-133.

PROMOTORA ESPAÑOLA DE LINGÜÍSTICA (PROEL). “Grupo ugro-finés”. $<$ http://www.proel.org/index.php?pagina=mundo/uraloyu/uralo/finougrica $>$ [Fecha de consulta: 04-08-2014]

REAL ACADEMIA ESPAÑOLA. (2009). Nueva Gramática de la Lengua Española. Morfología y Sintaxis I. Madrid, Espasa, pp. 82-126, 793-799. 
RODRÍGUEZ, J. R. y GARCÍA, M. Á. (2012). Meta Final ELE. Curso de español rápido. Madrid: Edelsa.

SCHWARTZ, B. y SPROUSE, R.A. (1996). "L2 Cognitive States and the Full Transfer/Full Access Model", Second Language Research 12: 40-72.

SUTROP, U. (2004). Estonian Language. Tallinn, Estonian Institute.

$<\underline{\text { http:} / / w w w . g o o g l e . c o m / u r l}$ sa $=t \& r c t=j \& q=\& e s r c=s \&$ source $=$ web $\& c d=1 \& v e d=0$ CB8QFjAA\&url=http\%3A\%2F\%2Fwww.utlib.ee\%2Fliber2012\%2Ftekstid\%2Fees tikeel.pdf\&ei=Crj4U6ncPMTcaLKBgugG\&usg=AFQjCNEv8Cqi1X7dPlnLTzFZG TXHs5b9nA\&sig2=EWSAslsnwexd7 nazEwHyw\&bvm=bv.73612305,d.d2s $>$ [Fecha de consulta: 04-08-2014]

TORRENS ÁlVAREZ, M.J. (2007). Evolución e historia de la lengua española. Madrid: Arco/Libros.

VV.AA. (2007). Plan Curricular del Instituto Cervantes, Centro Virtual Cervantes. $<\underline{\text { http://cvc.cervantes.es/Ensenanza/Biblioteca_Ele/plan_curricular/niveles/02_gram }}$ atica_inventario_a1-a2.htm> $<\underline{\text { http://cvc.cervantes.es/Ensenanza/Biblioteca_Ele/plan_curricular/niveles/02_gram }}$ atica_inventario_b1-b2.htm> $<$ http://cvc.cervantes.es/Ensenanza/Biblioteca_Ele/plan_curricular/niveles/02_gram atica_inventario_c1-c2.htm>

[Fecha de consulta: 23-08-2014]

VV.AA. (2012). Nuevo Prisma A1: Curso de Español para Extranjeros. Madrid: Edinumen.

WHITE, L. (2003). Second Language Acquisition and Universal Grammar. Cambridge: Cambridge University Press.

WHITE, L., VALENZUELA, E., KOZLOWSKA-MacGREGOR, M., y LEUNG, Y. I. (2004). "Gender and Number Agreement in Nonnative Spanish", Applied Psycholinguistics 25: 105-133 


\section{ANEXOS}

Errores producidos por alumnos de nivel A1:

- El capital de Ecuador es Quito.

- Ella es muy inteligente y un poco serioso.

- ¿Cuánto questo?

- Perdone, ¿cuanto questa esta?

- ¿Cuánto cuesta la mochila?

- ¿Cuánto cuesto el abrigo?

- ¿Cuánto cuestas las gafas de sol?

- ¿Cuánto cuestos los pendientes?

- Me mejor amigo es person muy interesante.

- Ella es *studienta.

- Ella es *studenta.

- El es cantaro.

- El es periodisto.

- El es futbolisto.

- Mi amigo se llama Karina. Ella vive en Oru. Ella es rubio y un poco bajo.

Errores producidos por alumnos de nivel A2:

- Y ¿que tu esta haciendo estas dias?

- Hay una lámpara a la izquierda de la sofá.

- Hay una lámpara a la derecha de la sofá

- Hay una lámpara al lado de la sofá.

- Yo tiene vacaciones pequeño.

- Pedro tiene 3 habitaciones, pero Juan sólo uno.

- La Juan casa no hay tantos habitaciones como la Pedro casa.

- Me llevo bien con Anne, porque ella es divertida en los clases de español.

- En algos lugares tuvimos el nieve.

- Entonces los frases en español son:...

- Yo salí ayer y el tarde fue muy largo.

- Tuve un paciente de Cuba, que era interesante. Este paciente fue una cubana, estaba casada con un chico de Finlandia.

- El padre está durmiendo. El madre está leyendo el periódico. 
- El español es el aficion para ella.

- $\quad$ Tengo que ir en un operacion en 30 minutos.

- Si necesitas un traducion, escríbeme.

- No se como es en espanol esto expresión.

- Perdon mama, esto es lo ultimo vez.

- Jaava tiene 30 y mas años y es chica muy activa pero un poco serioso.

- La abuela esta vienda la tele. La madre esta leyendo el periódico.

- ¿Ellas han comida paella alguna vez? Sergio ha estado en España nunca.

- Belen esta escribiendo la correa.

- El abuelo esta jugando a los cartos.

- No, es que no tengo dinero por el gasolin.

- Esta haciendo mucho cosas importantes.

- $\quad$ Aqui el tiempo ha sido muy bien 10-15 grados y mucho lluvia.

- Bebi mucho cerveza de Saaremaa, tienes que probar.

- Esto es un anglicismo, una palabra prestado.

- Estoy trabajando mucho también. Es que tengo que cerrar todo cosas de trabajo.

- Liia es la morena y alta y guapa mujer. Ella es muy simpático.

- Estoy trabajando mucho tambien. Es que tengo que cerrar todos cosas de trabajo.

- Es que yo trabaje mucho este semana

- En este semana es ultima clase de español.

- Este semana estoy trabajando mal.

- El es muy bueno persona.

- Natalja tienes pelo liso y morena.

- ¿Me puede dar un Coca Cola?

- ¿Me pone un Coca Cola por favor?

- ¿Puedes dar un cola por favor?

- En Granada es muy grande y grandioso Alhambra.

- Hoy llevo vestida gris y jacketa verde, muy bonita.

- iY que bonitas vestidas estoy comprando!

- Ella es guapa, morrena. Lleva camisa negro, pantalones. Tiene el pelo largo, risado. Tiene los ochos oscuras. Lleva gafas.

- Jaava lleva jersey azul y pantalones azul también y los botas. 
- El abuelo esta jugando del cartas.

- Raquel esta hablando por la telefono.

- (Natalja) Se es muy tranquilo y trabajadora.

- Despues esta comprando una bueno vestido y camisa.

- Es que ayer estoy cansado.

- Estoy muy sorprendido por los resultados.

Errores producidos por alumnos de nivel B1:

- ¡Tenemos que contener nuestra planeta de basura! ¡Gracias por su colaboración!

- Llamame, por favor, quando sabrás la día del operación.

- Este verano he nadado pocos veces en el mar.

- Me molesta televisión, por eso no tengo el tele.

- Me interesan los elexiones del gobierno.

- Muchos cruceros salen de Ushuaia y yo tambien fui a un crucero ronda del Cabo de Hornos y dentro un monton de islas, que forman, en verdad, un parte de Chile y donde por ejemplo Charles Darwin ha trabajado.

- He recogido unos clases de tango argentino, clases individuales.

- Durante los meses de verano tenemos algunos dificultades con agua por eso pedimos a ustedes ayudarnos ahorrarlo. Si necesitan regar los flores, pedimos regarlos por la mañana muy temprano o por la noche muy tarde.

- Todos escucharon el radio con padres y hermanos

- Tengo muchos fotos y quería hablar más cuando encontraremos!

- También espero que el operación de tu rodilla vaya bien.

- Me molestan las pausas entre las películas por el televisión.

- iVi pingüinos! El primero vez de mi vida.

- Me molesta estar en la prensa y ganar mucho publicidad.

- En este semana yo he visitado Córdoba tambien y en la semana pasada *viaja a Patagonia.

- Este nota está escrito para informarle de las normas como usar los recursos en este campin.

- Este mes he estado muy ocupado. 